\title{
Measuring and reporting life-cycle duration in insects and arachnids
}

\author{
HugH V. DANKS \\ Biological Survey of Canada (Terrestrial Arthropods), Canadian Museum of Nature, P.O. Box 3443, Station "D", Ottawa, Ontario, \\ Canada K1P 6P4; e-mail: hdanks@mus-nature.ca
}

Key words. Life-cycles, duration, rearing, instar, stage, demography, experimental design, statistics, insects, mites

\begin{abstract}
Some previous work on arthropod development is insufficiently detailed or incompletely reported. Much of the published information in this area is of limited use for the general analysis of life cycles. These difficulties arise primarily because many experiments do not control fully for the strain of the material (and even its specific identity) nor for rearing conditions, do not adequately take account of the complexity of life cycles and their stages, or are restricted to only part of the life cycle. For example, 285 such factors as variable numbers of instars, sexual differences, abbreviated or hidden stages and dormancies may mean that the "average durations" reported apply to an unknown mixture of developmental types. Nor are experiments always designed or results reported and analysed in a logical and transparent manner. Undefined terms may obscure what actual developmental intervals were measured. Highly derived developmental or demographic measures may obscure core data. Statistical information may be inadequate. Such pitfalls are reviewed here, suggesting ways to ensure that results on the duration of development are both valid for specific studies and more widely useful. General experimental difficulties, recommended background information that should be provided, recommended life-cycle intervals and their terminology, and recommended ways to report numerical and statistical information are briefly summarized in tabular form.
\end{abstract}

\section{INTRODUCTION}

How long does an insect's life cycle and its component stages last? The answer to that question, including how these durations are modified when conditions of temperature, food or other factors change, is a key piece of information for understanding the way of life of every species. But the question is surprisingly complex, and this paper examines the difficulties in defining stages, and in securing and expressing data on life-cycle duration. It suggests some procedures to be adopted or avoided for all kinds of studies, based on my overview of how key aspects of insect life cycles can best be summarized (Danks, 1987, 1991, 1992, 1994, unpubl. analysis).

Some of the conventions adopted to express durations of development during the life cycle differ among individuals, groups of scientists, and even journals. In addition, much of the information published is inadequate or incomplete, for various reasons. I have cited relatively few specific examples of such inadequacies here, because it is not my intention to embarrass particular authors. Moreover, procedures and summaries depend on the purpose of a particular experiment, which may have different needs than for the general analysis of life cycles. Nevertheless, I argue here that data should be presented in ways that enhance their broader value.

This paper aims to present a variety of relevant terms, difficulties and recommendations in one place. I hope thereby to encourage entomologists conducting the hundreds of studies carried out each year on the duration of insect development to ensure that their results are both valid and widely useful. By this means, they can be built upon to advance knowledge (like all properly published research) and not simply be "one-time" products of limited value.

\section{STAGES OF THE LIFE CYCLE}

Characteristic stages of the insect life-cycle are shown in Fig. 1, emphasizing immature stages. Exopterygotes omit the prepupal and pupal stages, of course. These basic stages are patterned in many different ways in different groups, including the omission or abbreviation of particular substages. The instars may be very similar to or very different from one another, and may include one or more modified resting stages.

In typical mites (as in tetranychids, for example), the successive immature stages are the egg, larva (usually six legged), protonymph and deutonymph. However, as in insects, different groups of mites have different life-cycle patterns. For example, some species have an additional nymphal stage; in others one or two stages are lost.

Egg stage. After oviposition, the egg hardens and may change colour. Other colour changes, especially darkening, are visible before hatch. The duration of embryogenesis is correlated with taxonomic placement (Order) (Detlaff, 1996). Many stages of embryonic development can be recognized by careful examination (Miya, 1965 for chrysomelids; Ingrisch, 1984 for tettigoniids; Gotoh et al., 1994 for mites), and in a more general way from conspicuous features visible externally, such as coloration or eyespot development. If development is delayed it can often be detected from such markers. In several species a resting stage immediately precedes hatch, so that the egg contains a fully formed pharate larva (e.g. Lymantria dispar L.). Hatch itself (exit of the larva from the chorion) usually is relatively rapid, although in some species the first instars remain for some time within structures associated with the eggs, such as a gelatinous matrix 


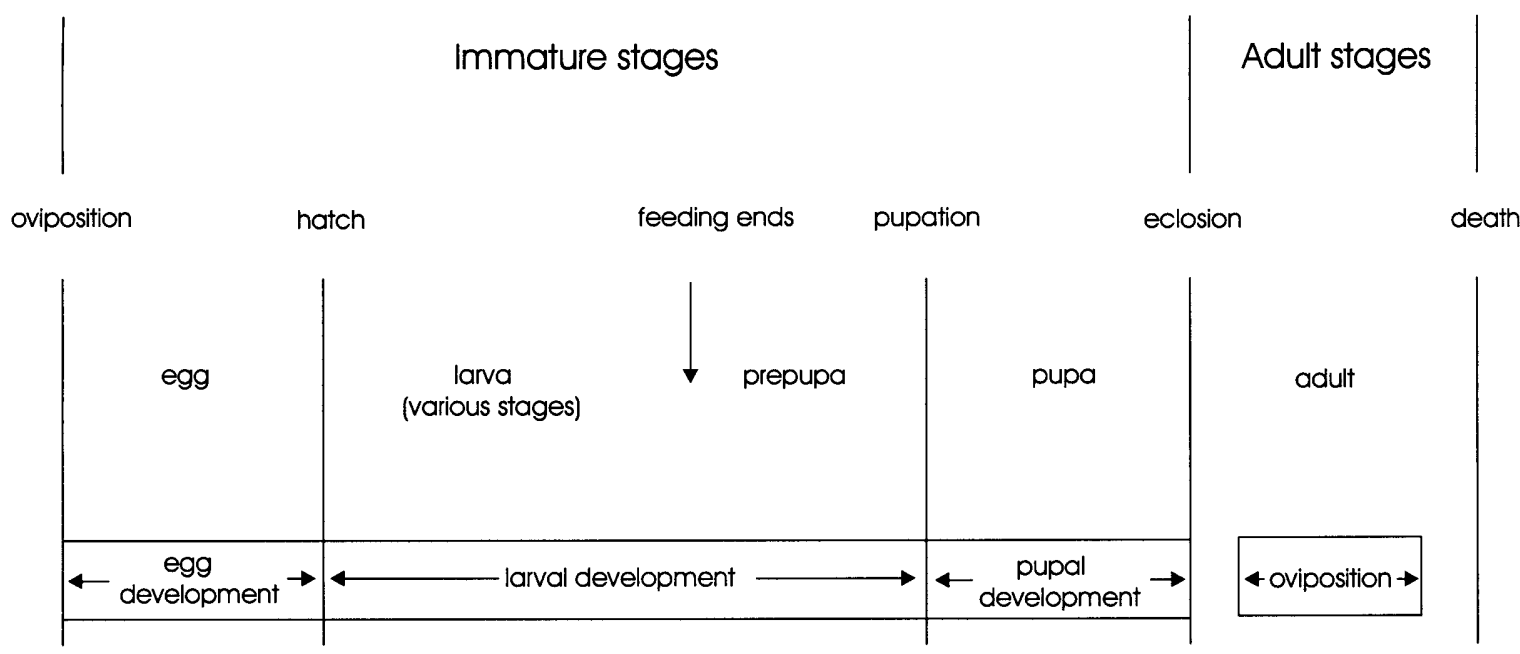

Fig. 1. Scheme showing visible stages of development in a typical endopterygote insect, emphasizing immature stages.

(e.g. Danks, 1971 for chironomids; Wiggins, 1973 for limnephilid caddisflies).

Larval stage. The major role of larvae in the life cycle is to feed and grow. Consequently, their structural and temporal patterns of development are related largely to the need to survive in particular environments (generally chosen by ovipositing females) and to acquire and use the food resources there.

In many species first instars differ from later instars, especially if they serve for dispersal (as in the planktonic first instars of Chironomidae: Davies, 1976), host finding (as in parasitoids that penetrate hosts from the host habitat) or protection of the resource from other individuals (as in the hyper-metamorphic first instars of many parasitic hymenopterans). Typically, first instars moult relatively rapidly to the second instar, and in some species do not feed [Harvey, 1957 for the tortricid moth Choristoneura fumiferana (Clem.); Strickman et al., 1997 for the pholcid spider Crossopriza lyoni (Blackwall)]. Depending on the group or species and on its particular life cycle, other instars are modified. For example, the pre-adult (second nymphal) instar in several Acaridiae is the hypopus, a modified resting instar.

The number of instars typically is large in apterygotes (e.g. up to 30 in silverfish: Nishizuka et al., 1998) and primitive exopterygotes. Mayflies normally have 15-25 instars, but from as few as 10 to as many as 52 depending on the species (Trost \& Berner, 1963; Clifford et al., 1979; Fink, 1980; Brittain, 1982). There are about 12-24 instars in stoneflies (Vaught \& Stewart, 1974; Baumann, 1987), and 10-15 in dragonflies (Westfall, 1987). On the other hand, usually there are only five instars in Heteroptera. Advanced endopterygotes typically have only 3-4 instars (many Coleoptera and most Diptera) or 4-7 instars (most Lepidoptera and Hymenoptera). Although in many species, especially of endopterygotes, the number of instars is fixed, in some species the number can vary depending on the conditions of temperature and food experienced. For example, variations in the number of instars are known in spiders (Miyashita, 1997), ticks (Dautel \& Knülle, 1997), mayflies (Brittain, 1976), stone- flies (Vaught \& Stewart, 1974), dragonflies (Rivard \& Pilon, 1977), grasshoppers (Kawano \& Ando, 1997), beetles (Beck, 1971; Gerard \& Ruf, 1997), moths (Neunzig, 1969; Morita \& Tojo, 1985; Clare \& Singh, 1990; Kamata \& Igarashi, 1995), and other groups. The developmental routes of individuals with different numbers of instars are not equivalent, and data on instar durations have to be recorded separately for these different individuals.

At any given time, each instar can be in one of three states: active and feeding; inactive and moulting; or inactive and dormant. Moults can occupy a significant fraction of the time spent in the larval period, especially at lower temperatures; e.g. $43 \%$ of the penultimate instar in the geometrid moth Epirrita autumnata (Borkhausen) and $50 \%$ in the chrysomelid beetle Galerucella sagittariae Gyllenhal at $12^{\circ} \mathrm{C}$ (Ayres \& Maclean, 1987). Moreover, larval moults, pupation and adult eclosion are prevented at low temperatures that are otherwise suitable for growth and development.

Dormancies and related responses can greatly prolong life-cycle durations. Many life-cycle programmes are structured by diapauses that suppress larval development in response to environmental cues of various kinds (Danks, 1987). Beyond such clearly marked developmental delays, the rate of growth can be modified indirectly by photoperiod (Danks, 1987, Table 3); and simple quiescence can be caused directly by unsuitable food or by conditions that are too cold or too dry (see Delays). The possibility of such interruptions in the life cycle prompts care in developing experimental protocols to measure life-cycle duration.

Once feeding ends, the final-instar larva enters the prepupal stage (Fig. 1). A few authors have restricted the use of this term, like the term propupa for Thysanoptera, to a separate preadult instar. The end of feeding can sometimes be detected by direct observation, although this is often inadequate for rapid checking during experiments. It is also signalled by changes in behaviour or by changes in appearance. For example, fully grown larvae may spin a cocoon, or leave the food to wander in search of a pupa- 


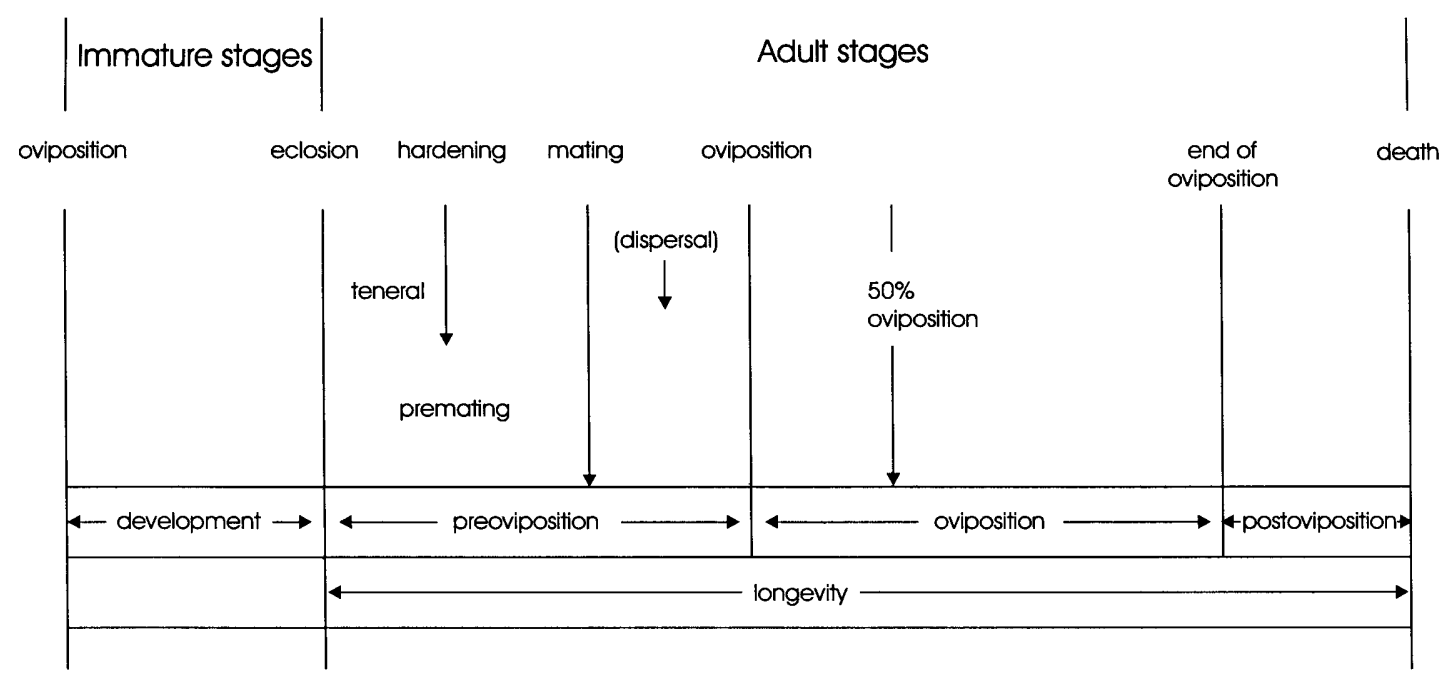

Fig. 2. Scheme showing visible stages of development in a typical oviparous insect, emphasizing adult stages.

tion site (Richard et al., 1986). Prepupae normally have thickened or more conspicuous anterior segments, corresponding to the thorax of the pupa, which are easily visible in the larvae of Diptera such as Chironomidae, for example. Duration of the prepupal stage, unlike that of the larva that precedes it, does not depend directly on food, but instead may be determined partly by the availability of suitable pupation sites as well as by temperature.

Pupal stage. Substages of pupal development can be recognized from selected characters such as leg or wing rudiments, eyespots or other pigmentation, thoracic or abdominal setae, and internal reproductive structures. Colour darkens markedly as eclosion nears. The characteristic U-shaped respiration curve of pupae shows decreased metabolism after pupation and a larger increase before eclosion (Schneidermann \& Williams, 1953).

The substages of pupal development have not been characterized in most species, although some diapause stages or markers have been documented (e.g. Ohnesorge, 1979; Hackett \& Gatehouse, 1982; Kusters \& Herrebout, 1989).

Adult stage. Several relatively easily recognized substages of adult life are important for assembling data on the life cycle (Fig. 2). These substages are generally visible in mites as well as in insects. Only Collembola and other primitive hexapods continue to moult during adult life.

Upon eclosion from the last-instar larva or pupa, the cuticle is still soft, and the adult is teneral. Adults harden very rapidly in some species, but in others the process of sclerotization may take many days, as in dragonflies. In species that chew their way out of a pupal cocoon, mandibles must harden before this is possible, and therefore "emergence" is delayed for some days after adult eclosion (see Hidden stages).

Information on oviposition is very important for understanding the duration of the life cycle: the life cycle of a typical individual begins when it is deposited as an egg, but determining the corresponding endpoint depends on the temporal pattern in which eggs of the next generation are produced. In most species mating alters preoviposition or oviposition periods or longevity (see Laboratory rearing).

In many species the preoviposition period is longer than the teneral period, the premating period or both, for two reasons. First, substantial ovarian development, often preceded or accompanied by adult feeding, may be required. For such species, the supply of adult food helps to determine the pattern of oviposition (see also Laboratory rearing). Second, many species include a period of dispersal early in the life of some or all adults before eggs are developed (see Johnson, 1969; Dingle, 1972 for general information on this "oogenesis-flight syndrome"). In polymorphic species (Zera \& Denno, 1997), the developmental pathway usually differs between flying and nonflying individuals. Long-distance flight takes place before and after reproductive diapause in some species (e.g. Oku, 1983), and a similar phenomenon on a smaller scale is common in many other insects (Wissinger, 1997). In such species it may be difficult to assess oviposition responses under laboratory conditions.

To summarize oviposition, its temporal pattern as well as the beginning and end must be described. Normally, more eggs are laid soon after oviposition begins than at the end of the oviposition period. A few species oviposit in two or more separate bouts, such as mosquitoes that mature egg batches after successive meals, and long-lived adults that survive for more than one season (Danks, 1992).

Some other species, especially those with long-lived adults, survive for some time before they die without depositing any more eggs (Fig. 2). Such postoviposition adults have been noted in many laboratory studies, and "spent" females have also been reported under field conditions (e.g. Matalin, 1998). The fact that some adults survive after oviposition ends, and the fact that the distribution of oviposition through the oviposition period is usually skewed, means that the commonly measured 
intervals of preoviposition period and longevity are inadequate on their own to characterize oviposition.

Omitted or abbreviated stages. Various groups or species have reduced or eliminated some of the characteristic life-cycle stages shown in Figs 1 and 2. Such changes may serve to remove or protect vulnerable stages or to accelerate the life cycle. Apart from reduction in the number of instars, one of the commonest changes is reduction of eggs through larviposition or viviparity, as in tachinids, some sarcophagids and aphids. Eggs or larvae or both can be retained in the mother, even resulting in an adult to adult life cycle, as in ovoviviparous pyemotoid mites (Wrensch \& Bruce, 1991). A few parthenogenetic species can produce offspring even before adult eclosion, as in the aphid Schizaphis graminum (Rondani) (Wanjama \& Holliday, 1987), and in some individuals of the black fly Prosimulium ursinum (Edwards) (Carlsson, 1962 as Simulium). Non-feeding instars also occur commonly (e.g. some first instars as already noted; specialized dormant stages). Adult stages are abbreviated by features such as parthenogenesis (mating is unnecessary), adult eclosion with eggs fully developed (ovarian development is not necessary), and rapid oviposition in a single batch.

The many differences of this sort make it more difficult to compare the durations of different stages and substages among species. Care must be taken not to compare or average statistics for substages that are not equivalent.

Hidden stages. In practice, not all of the moults between successive stages are readily observed, so that statistics on duration are much more difficult to collect. For example, egg hatch cannot be observed directly in gall formers, endoparasitoids and other species that live inside their food resources. The prepupal to pupal change is not visible without special procedures in species that pupate inside robust silken cocoons, or in dense substrates such as soil. In cyclorrhaphan Diptera, pupation takes place inside the puparium (the rounded off, sclerotized exoskeleton of the third-instar larva) up to a few days after pupariation, and hence normally can be determined only by dissection.

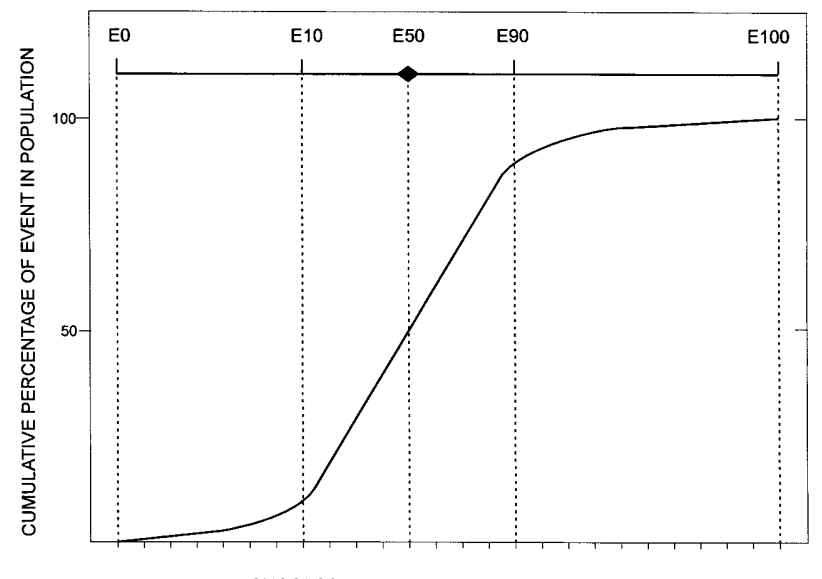

SUCCESSIVE DAYS OF OCCURRENCE OF EVENT

Fig. 3. Stylized cumulative event curve and event line, illustrating means to summarize key measures during the interval over which an event occurs in the population. For further explanation, see text.
The pupal to adult change is difficult to observe directly in species that remain quiescent in a pupal cell or relatively robust cocoon after eclosion and while still teneral. "Adult escape" or "emergence" requires up to several days after eclosion in species of chrysomelids, curculionids, and other beetles (e.g. Buckingham \& Bennett, 1981; Jackson \& Elliott, 1988; Purcell \& Balcuinas, 1994) and in various Hymenoptera (e.g. Danks, 1970, p. 332). Additional delays occur if the adults subsequently are dormant, as in xylocopine bees of the genus Ceratina (e.g. Maeta et al., 1992). The post-eclosion interval can be estimated in adults isolated from their cocoons by the fact that meconium normally is discharged when exit from the pupal cell would have occurred.

Sexual differences. In many species rates of development differ between the sexes. Conventional wisdom suggests that males develop more rapidly because they are smaller or because protandry may be advantageous for mating, whereas females develop more slowly because they are larger or can increase fecundity by further feeding (cf. Danks, 1994). However, this pattern is by no means the only one (Honěk, 1997).

\section{MEASURES OF DURATION}

Temporal programmes of development or life-cycle pathways of many species are relatively complex, so that no simple set of universal experiments or measurements can give unambiguous information about substage durations in every species. This section briefly provides some context for the choice and recording of intervals, and also considers developmental delays, which complicate assessments of duration in many species.

Temporal patterns and key measures. Two types of temporal information can be recorded about the life cycle of an individual. First, each individual experiences unique events, such as hatch and pupation, which together delimit larval duration. Second, patterned events may take place within a particular interval, notably the pattern of oviposition within an individual oviposition period (Danks, 1994), which is "averaged" to delimit the end of the current generation and the start of the next. Such patterns can be described in part by means of summary statistics, but accurate documentation of the pattern is complex.

Summary data such as the date by which $50 \%$ of the eggs are deposited can be obtained either by averaging for the population as a whole (the date on which $50 \%$ of the eggs have been deposited by the whole population) or by averaging individual records (the mean of the dates on which each individual has deposited $50 \%$ of its eggs). These values are not always the same; the former is normally preferable.

Key statistics include the first, 50\%, median, and last occurrences. Especially when the temporal pattern is more or less normally distributed (and hence sigmoid in a cumulative plot), valuable information is also provided by the $10 \%$ and $90 \%$ levels, which correspond closely to the inflections of the sigmoid curve (see Fig. 3), and it is feasible to express such information using marked lines (top 
part of Fig. 3), a system originally developed to summarize emergence patterns (Corbet \& Danks, 1973). This system also allows departures from normality, which are not expressed by mean and variance alone, to be visualized readily.

The day or interval during which emergence or oviposition is maximal can also be given: oviposition in many species rises to a plateau, is maintained for a period, and then declines, and the oviposition rate during this "peak" period has been regarded as the most informative statistic for demographic analysis (Sabelis \& Janssen, 1994).

How a distribution can best be described depends especially on whether it is skewed. Medians (which are less affected by abnormal values) are earlier than means even for common patterns that are mildly skewed with an early peak and a longer tail. Deciding how to summarize bimodal patterns, or multimodal patterns with peaks separated by long intervals, is especially challenging. Statistics for each peak as well as for the total duration should be offered.

The choice of statistics to summarize these temporal events depends partly on the objectives of the specific work, but individual researchers should also endeavour to express their results so that the data are usable for other purposes. The typical positive skew of temporal distributions such as oviposition makes the first part of the distribution easier to specify than its longer tail. Indeed, the end of the distribution depends on a negative finding (such as no emergence) and hence may be difficult to document. Moreover, generating reliable statistics about the whole, or the later part, of the distribution may be hindered by accumulating mortality (potentially independent of the pattern of oviposition, for example) and by the need for lengthy studies to ensure that events are complete. On the other hand, the start of the distribution is very sensitive to sample size, because an earlier start will be recorded from a larger sample (Howe, 1967). The 50\% statistic is of great value for general analyses (such as life-cycle or stage duration as such), whereas the $10 \%$ statistic (which avoids some of the problems associated with the beginning of the distribution but nonetheless provides a reliable indication of its onset) is likely to be especially valuable in a demographic context. Consequently, graphical overviews (such as Fig. 3) are very useful in addition to standard summary statistics.

An additional problem is created if the quality of individuals changes during the interval being summarized. Later in the oviposition period there may be reductions in the size or hatching success of eggs (Unnithan \& Delobel, 1985; Wasserman \& Asami, 1985; Mousseau \& Dingle, 1991), or changes in the sex ratio (Tepedino \& Torchio, 1982; Danks, 1983a), or in the incidence of diapause (Danks, 1987, Table 15). Such changes in quality make later individuals not equivalent (in terms of population dynamics for example) to earlier ones. More detailed data, or some measure of potential, may then be more informative than simple data on occurrence: $50 \%$ female oviposition rather than $50 \%$ oviposition, or $50 \%$ of individuals that will not enter diapause rather than $50 \%$ of individuals, for example. Fortunately, these effects are relatively small in most species and can be disregarded because the simpler measures produced by treating all individuals as equivalent allow easier comparison among species.

Substantial differences in individual development times are relatively common in both field and laboratory, because of genetic variation and the local effects of food and environmental conditions. The average coefficient of variation was about 8 or $9 \%$ in analyses made by Honěk (1997). Different life-cycle "durations" can be recorded for multivoltine species and for those reared at a range of temperatures; but different substages of the life cycle are affected differently by changed conditions, so that there is no assurance that the key measures used to summarize the substages will retain a fixed relationship to one another in different regimens or at different times of year. For example, one stage of development is likely to be delayed more than another at low or at high temperatures (e.g. Lamb \& Gerber, 1985). Statistics used to compare stage duration have to be collected under equivalent conditions. Most of the results of different authors on the same species are different because there were minor differences in factors such as diet (cf. Lamb et al., 1987).

A particular problem arises because in many species the population is divided into two or more sets with different characteristics and patterns of variation. For example, the anthomyiid fly Delia radicum (L.) shows complex differences among and within populations, with "early emergers" - compared to "late emergers" - showing faster development at the maximum developmental temperature, lower day-degree requirements for emergence, and usually no developmental delay at high temperatures (Turnock \& Boivin, 1997). These subsets of the population cannot meaningfully be analysed together.

In any event, more rather than less comprehensive summaries of temporal patterns should always be provided. In addition, as for all research, statistical treatments of the sample data require that mean, number of individuals, and error terms all are provided explicitly, as discussed under Analysis of results.

Total and component intervals. When data are collected on the durations of a number of substages (different larval instars or different life stages), the sum of average durations for each stage may differ from the average for the total interval (larval development, or life cycle). Nearly always, the summed duration is longer (Danks, unpubl. analysis). Small differences (e.g. 0.1 days) result especially from rounding of the individual means. However, differences between summed and directly averaged durations at some temperatures may be 1 or $2 \%$ of the life cycle in some species (e.g. Braman \& Yeargan, 1988) or rarely up to 5\% (Ellsbury, 1991). Such divergences probably stem from experimental variation in the individual substages (including sample sizes that are too small to provide robust means), and from the fact that the substage data sets are not normally distributed.

Because the total interval is of most interest in studying the life cycle as a whole, whereas the substage durations 
are of most interest for answering more specific questions, it is helpful to have both statistics, including the data necessary to assess the pattern of sample variation. In addition, data for different routes of development, even for the simplest cases of individuals with different numbers of instars, should be collected and summarized separately, as already noted under Larval stage.

Delays and programmes. Delays in the life cycle, which also change the temporal relationships between stages, stem from four causes: integral parts of development such as the moult (see Larval stage); unsuitable conditions such as inadequate food; short-term responses to specific stimuli; and programmed developmental controls such as diapause.

The performance of many phytophagous species varies greatly on different foods. For example, in the tortricid moth Epiphyas postvittana (Walker) the effects of food and of temperature on the rate of larval development and size cause subsequent reproductive performance to vary more than fifty-fold (Danthanarayana et al., 1995). There are many other examples of the effect of food quality on developmental period, oviposition period and longevity, as well as on such things as size, fecundity and sex ratio (e.g. Pachori \& Gargav, 1997). Food quality can depend on food plant species, strain, and condition including freedom from plant pathogens (DeAngelis et al., 1993). The developmental rates of parasitoids are likewise affected by the nutritional and physiological status of the host (Rivers \& Denlinger, 1995).

In addition to food quality and low temperatures, conditions that may limit rates of growth or delay development to the next stage directly include unsuitable humidity (e.g. Smith, 1993), crowding (e.g. Kotaki et al., 1993; Applebaum \& Heifetz, 1999) or large numbers of parasites per host (e.g. Collins \& Grafius, 1986), isolation in species that grow better in groups (Holbrook \& Schal, 1998), and infection by pathogens such as viruses and microsporidans (e.g. Cranford, 1972; Wilson, 1980; Bauer \& Nordin, 1988). Depending on the availability of adult food, adults of the medfly Ceratitis capitata (Wiedemann) may be in "waiting" or "reproductive" modes that strongly influence longevity (Carey et al., 1998). Careful attention to all of the conditions of rearing therefore is required for studies on stage duration (see also Laboratory rearing).

Some species require specific stimuli to complete a stage. For example, egg hatch in mosquitoes from snowmelt pools is stimulated by lowered oxygen concentration in the water surrounding the eggs (Wood et al., 1979), reflecting the presence of bacteria on which the larvae feed. Adult emergence of the taeniopterygid stonefly Oemopteryx fosketti (Ricker) from the final larval instar is delayed until ice break-up (Dosdall \& Lehmkuhl, 1979).

In addition to direct effects, many species have pronounced or subtle intrinsic or environmentally modified responses. The many components of these programmed responses alter developmental rates or lead to pronounced developmental delays, as summarized by Danks (1987, e.g. Fig. 35). For example, some butterflies tune the rate of development according to whether time before the end of the season is surplus or in short supply (Nylin, 1996). The responses depend on cues monitored in current or earlier life-cycle stages, even including the previous generation, cues that can include photoperiod, light intensity, temperature level, thermoperiod, food, moisture or humidity, and density (Danks, 1987, 1994, Table 2).

The duration of the life cycle or its substages therefore can change markedly in response to many factors, and can be influenced over long periods. Delays and other differences can stem too from genetic polymorphisms and strain differences (see Status of material, below) as well as from the actual conditions experienced. Consequently, studies of life-cycle duration should be established in as wide a biological context as possible.

\section{INTEGRATING INFORMATION}

Many individual studies are aimed at integrating information on development. How this integration is carried out affects both current conclusions and the usefulness of the results for later comparison and synthesis by others. There are three major approaches to integrating information about the duration of development. First, absolute and relative durations of the stages can be examined. Second, requirements for development, for example of temperature, can be summarized. Third, the data can be subjected to demographic analysis. All of these approaches require that the original data on life-cycle intervals are precise and consistent.

Relative durations of substages. The relative durations of different life-cycle stages show more or less consistent taxonomic patterns. Detailed analysis is beyond the scope of this paper, but some characteristic durations are well known. For example, most adult Coleoptera are relatively long lived (Danks, 1992), unlike adults of such groups as mayflies (Clifford, 1982) and gall midges (Sunose, 1985). The preoviposition period is very short in small parasitic Hymenoptera (Cronin \& Strong, 1990 for a mymarid; Yu et al., 1984 for a trichogrammatid), but prolonged in many long-lived beetles, as might be expected, as well as in some other taxa (Tauber et al., 1992 for a lacewing), especially at low temperatures (Arbogast, 1984 for an anthocorid). The pupal period is relatively long in some Diptera (Quiring \& McNeil, 1985 for an agromyzid). The rate of oviposition is determined partly by phylogenetic placement (subfamily) in mites (Zhang, 1995). In addition to these taxonomic patterns during continuous development, the stages of life-cycle delays such as diapause often are characteristic of particular taxa (Danks, 1987, Table 9).

Departure from such taxonomic patterns may indicate adaptations of groups or species that accord with their ecological relationships. The most extreme adaptations involve elimination of stages (as in summer viviparous generations of aphids which reproduce rapidly on ephemeral host plants). Voltinism and rate of development typically are related to habitat. For example, relatively rapid immature development is characteristic of many species from dung and carrion, decaying vegetation and fungi 
(e.g. OConnor, 1994) and temporary pools and streams (e.g. Wiggins et al., 1980; Delucci \& Peckarsky, 1989). Prolonged adult life in some species is correlated with cool or unpredictable habitats (e.g. Sota, 1994; Topp, 1994). Detailed information about the biology under field conditions of any species under study therefore is very helpful to interpret durations of development under laboratory conditions.

Detecting delays. Some life-cycle delays are very obvious. For example, some individuals enter diapause and will not resume development for many months whatever the conditions whereas their siblings develop directly and emerge within a few weeks. In other species, the duration of development appears to vary continuously over a long interval. In some instances the variation indeed is continuous (although its extent may nevertheless be an adaptive feature and not just the result of variation in microsite conditions). In other species, however, slower but not more rapid individuals have a programmed delay. Such a situation often can be detected by appropriate data analysis. Nishizuka et al. (1998) transformed cumulative percentages of the frequency of a given duration of development into probits. "Diapause" and "non-diapause" groups could then be distinguished because lines through the sets of points had different slopes.

Interstage correlations. Within a species, the duration of one stage may be correlated with that of another, based on the common direct effect of temperature on metabolism, on resource availability, or on other factors.

Generally, all substages last longer at lower temperatures within the normal range, but because different stages have different upper and lower limits their relative durations may change especially near the extremes. For example, egg and pupal development in the scolytid beetle Ips avulsus Eichhoff are shorter at $35^{\circ} \mathrm{C}$ than at $32^{\circ} \mathrm{C}$, but larval development is longer (Wagner et al., 1988). Moreover, differences in temperature limits among stages would be expected in species in which the stages have different natural habitats. For example, eggs laid in soil experience very different conditions than surface or leaf-feeding larvae. Stage differences suggest that great care is necessary when laboratory conditions are selected as "standard" for work on a particular species, and in the analysis of data for conditions outside the central or optimum range of each stage.

Factors other than temperature can change relative stage durations. For example, at higher humidities the preoviposition period of the tick Anocentor nitens (Neumann) is reduced, but the oviposition period extended (Silva et al., 1997). Short-term delays (see above) also alter relative stage durations.

Adjustments of life-cycle duration by means of diapause in a particular stage may be correlated with other developmental parameters. Typically, larvae destined to diapause develop more slowly than those developing directly (Danks, 1987, pp. 207-208 and Table 34). Different data for the two "kinds" of individuals may then be inadvertently grouped. Individuals of many species that enter diapause later tend to have a shorter or less intense diapause, so that all individuals end diapause at about the same time (review by Danks, 1987, p. 135). Adult Ptinus beetles that come from larvae that have been in diapause spend less time in the cocoon after eclosion than do adults originating from larvae not in diapause (Howe, 1962). Such responses alter the relative duration of different stages.

The experience of diapause alters subsequent developmental or reproductive parameters in some species (review by Danks, 1987, pp. 39-40). Postdiapause adults of the satyrid butterfly Mycalesis perseus (F.) have shorter oviposition periods and reduced fecundity compared to non-diapause (wet-season) individuals (Braby \& Jones, 1995). Species may be affected by conditions over the long term even in the absence of diapause. Maternal and paternal as well as developmental temperatures have different effects on some traits in Drosophila, so that conditions have to be standardized for at least two generations before experiments are conducted (Crill et al., 1996).

Resources are acquired during the life cycle of many species for eventual use in reproduction. In species with non-feeding adults that acquire all reproductive resources in the larval stage, the preoviposition period typically is short, as in mayflies, typical lymantriid and other moths with wingless females, and the pitcher-plant mosquito Wyeomyia smithii (Coquillet) (Moeur \& Istock, 1980; Bradshaw \& Holzapfel, 1992). In the same way, larval developmental time (i.e. the duration of resource acquisition) in populations of the mosquito Aedes togoi (Theobald) is correlated with the presence of autogeny, which greatly shortens the preoviposition period because blood feeding is not necessary before egg development (Sota \& Mogi, 1995). In many species, larvae that develop more slowly, as at lower temperatures, reach a greater size (reviews by Danks, 1987, pp. 213-214, 1994, pp. 9-10) and are more fecund. Even though adult reproduction is delayed, and in seasonal environments it often will be anyway whether larvae develop faster or slower, more eggs are deposited by these larger individuals. Conversely, rapid development may reduce mortality from natural enemies in less protected microhabitats (e.g. Cornell, 1990 for leaf miners versus gall formers). Immature developmental rate therefore interacts in a complex way with demographic parameters such as the rate of increase, and even within a species interstage correlations depend especially on trade-offs between growth rate and the timing of reproduction (e.g. Stam et al., 1996).

Serial correlation in the duration of life-cycle stages also has been shown by selection experiments. For example, lines selected for longer larval development in the tephritid fly Bactrocera cucurbitae (Coquillet) initiated mating later (Miyatake, 1997; Miyatake \& Shimizu, 1999); but not all selections for developmental rate produce correlated effects (Rodruigez-Saona \& Miller, 1995).

Relationships to temperature. Developmental rates change according to temperature, food and other conditions. Information on these differences or requirements 
has most often been integrated through the analysis of temperature sums (day-degrees) and thresholds for development. As might be expected, several general relationships are evident. For example, the lower developmental threshold generally increases with increasing temperature sum (Honěk \& Kocourek, 1990; Honěk, 1996a). Thresholds and day-degree requirements depend on the group, and hence on evolutionary history (cf. Pritchard et al., 1996), as well as on the features of the natural habitat of a given species. Thus stoneflies are a cold-adapted group, and those dwelling in cold streams have developmental thresholds below $5^{\circ} \mathrm{C}$ (Mutch \& Pritchard, 1986; Økland, 1991).

Temperature requirements can be modelled using a number of mathematical descriptions. Relevant theory has been reviewed many times (e.g. Wigglesworth, 1972; Laudien, 1973; Marshakov, 1984; Wagner et al., 1984a; Danks, 1987), and a variety of models for development continue to be presented (e.g. Logan et al., 1976; Sharpe \& DeMichele, 1977; Taylor, 1981; Regnière, 1982, 1984; Hilbert \& Logan, 1983; Wagner et al., 1984b, 1985; Hilbert, 1995; Lactin et al., 1995). The relationship of developmental time and temperature is complex: different developmental stages have different developmental parameters (Lamb et al., 1984), and many factors interact. Therefore, the effect of food and humidity on developmental rate may be different at different temperatures, and most visible near the optimum temperature (Lamb \& Loschiavo, 1981; Hagstrum \& Milliken, 1988).

One of the earliest models, still commonly used, relies on the fact that over the central portion of the typically more or less sigmoid developmental rate curve (Davidson, 1944) the rate of development is related linearly to temperature. Then:

$$
\mathrm{K}=\mathrm{D}\left(\mathrm{T}-\mathrm{T}_{0}\right)
$$

where $\mathrm{D}=$ developmental period; $\mathrm{T}=$ temperature; $\mathrm{T}_{0}=$ thermal constant threshold (the theoretical lower threshold of development); $\mathrm{K}=$ thermal constant (time by temperature requirements above the threshold to complete development). Alternatively:

$$
\mathrm{V}=\mathrm{aT}+\mathrm{b}
$$

where $\mathrm{V}=$ rate of development $(1 / \mathrm{D}) ; \mathrm{a}(=1 / \mathrm{K})$ and $\mathrm{b}(=$ $\left.-\mathrm{T}_{0} / \mathrm{K}\right)$ are constants.

The constant, $\mathrm{K}$, is the thermal constant or temperature sum (time $\times$ temperature above the threshold) required to complete development. Extrapolating the rate, V, to 0 gives a "threshold" for development, $\mathrm{T}_{0}$. However, because the rates of development are very sensitive to temperature and useful models depend on accurate observations, modelling will be in vain unless experiments are rigorously designed to control for or optimize strain, sample size and replication, chosen temperature intervals, calibration of experimental chambers, actual conditions experienced (as modified by local effects or insect behaviour), frequency of observation, and patterns of mortality (see Difficulties with available data, below).

Most models including equations (1) and (2) describe sections outside the central portion (i.e. near the develop- mental zero and at high temperatures) less effectively. Comparisons of some models are provided by Lamb et al. (1984), Wagner et al. (1984b) and Briere \& Pracros (1998). Thermoperiods or other daily fluctuations in temperature create great difficulties for most mathematical descriptions, because the effects of temperature are not simply linear or additive. Differences between instars in the lower limit for development may confound attempts to model or predict development as a whole (e.g. Manel \& Debouzie, 1997).

The "developmental threshold" can be estimated in several ways, but it is not normally an absolute temperature because very slow development may continue even below the estimated value. For example, $\mathrm{T}_{0}$ derived from equation (1) is at about $8 \%$ (not $0 \%$ ) of the maximum developmental rate according to the non-linear model of Lamb (1992). Choice of a descriptor such as $\mathrm{T}_{0}$ therefore depends on its intended purpose. In particular, the difficulties of modelling close to the threshold advise strongly against extrapolating beyond the range of temperature over which the data were collected in the first place (Liu et al., 1995). In many species, lower temperature limits increase through successive stages, so that temperature requirements for later stages such as adult eclosion are higher than for earlier ones such as larval growth. Examples include increasing lower limits for egg development, larval development and adult maturation (Musolin \& Saulich, 1995), early larval and late larval instars (Lutz, 1974), larval growth and pupation (Rühm, 1970), and larval development, pupation, and adult emergence (Danks \& Oliver, 1972). Such trends complicate the modelling of whole life cycles.

All models are simply mathematical descriptions of empirical data (although some have claimed a more direct theoretical relationship to metabolic rate, such as enzyme kinetics). Therefore, many different models that describe the data within acceptable limits can be generated (e.g. Lamb et al., 1984). Consequently, highly transformed data applicable to a single model, even the simple one of equations (1) and (2), usually are less useful in the long run, that is for purposes other than deriving a particular model under discussion, than the original data on substage durations. As a result, much of the analysis and modelling of developmental rates that has been published recently is unusable for the comparison of life cycles.

Demographic analysis. Demographic analysis integrates information on life-cycle duration by generating key statistics from idealized mathematical patterns describing trends in population numbers. Some commonly used statistics $\left(r_{m}, R_{0}\right)$ emphasize the change of numbers with time; others $(G, T)$ express temporal aspects - the element of most interest here - directly. All statistics focus especially on the numbers of female offspring and the time at which they are produced by adults of the previous generation (see, for example, Birch, 1948; references in Whittaker \& Goodman, 1979; Hulting et al., 1990; Carey, 1993; Sabelis \& Janssen, 1994). Calculations typically are made easier by using approximate rather than exact formulae. 
$r_{m}$ (or $r$ ), the intrinsic capacity for increase, is the constant by which numbers increase during a period of exponential growth (and hence with stable age distribution), when increases are entirely unconstrained by environmental or density-dependent limitations. Hence:

$$
\frac{\mathrm{dN}}{\mathrm{dt}}=r_{\mathrm{m}} \mathrm{N}
$$

where $\mathrm{N}=$ number of individuals in the population; $\mathrm{t}=$ time. A more exact calculation, summing the production of females across all age intervals when oviposition occurs, is provided by Sabelis \& Janssen (1994).

$\mathrm{R}_{0}$, the net reproductive rate, is the number of daughters in one generation divided by the number in the previous generation:

$$
\mathrm{R}_{0}=\sum_{\mathrm{o}}^{\infty} 1_{\mathrm{x}} \mathrm{m}_{\mathrm{x}}=\frac{\mathrm{N}_{\mathrm{o}}(\mathrm{t}+1)}{\mathrm{N}_{\mathrm{o}}(\mathrm{t})}
$$

where $1_{x}$ is the number of individuals surviving at the beginning of age interval $x ; m_{x}$ is the age-specific fertility ("fecundity").

$\mathrm{G}$, the generation time, sums the age-specific fertility as a function of the reproductive rate, which can be approximated (Dublin \& Lotka, 1925) as:

$$
\mathrm{G}=\sum \frac{1_{\mathrm{x}} \mathrm{m}_{\mathrm{x}} \mathrm{x}}{1_{\mathrm{x}} \mathrm{m}_{\mathrm{x}}}=\sum \frac{1_{\mathrm{x}} \mathrm{m}_{\mathrm{x}} \mathrm{x}}{\mathrm{R}_{0}}
$$

$\mathrm{T}$ is the age of peak oviposition (and hence an approximation of the generation time), and therefore is sometimes used too for generation time.

Such equations instead can be written in exponent form, for example:

$$
\begin{aligned}
& \mathrm{R}_{0}=\mathrm{e}^{\mathrm{r}_{\mathrm{m}} \mathrm{G}} \\
& \text { or } \quad \mathrm{G}=\frac{\log _{\mathrm{e}} \mathrm{R}_{0}}{\mathrm{r}_{\mathrm{m}}}
\end{aligned}
$$

Because developmental rate (when do females emerge and start ovipositing?) is much more important to $r_{m}$ than the oviposition rate, demographic analysis usually accentuates the start of oviposition, using the mean interval to first oviposition. Alternatively, it focusses on the peak of oviposition, a relatively short interval early in the oviposition period when daily egg production is at a maximum (see Sabelis \& Janssen, 1994). Conversely, eggs deposited later than $2 \mathrm{G}$ after emergence do not contribute significantly to $r_{m}$ (Abou-Setta \& Childers, 1991), and hence $r_{m}$ can be estimated from information at $G$ and 2G.

Demographic conclusions therefore depend partly on the nature of the life-cycle data that are collected (e.g. Draye \& Lints, 1996) as well as on the choice of a fitness measure (e.g. Danthanarayana et al., 1995). Consideration of life cycles from this demographic perspective (e.g. Roff, 1992; Stearns, 1992) has tended to focus on population aspects by elaborating models from a small number of demographic measures, usually without the empirical data to fully test them and with a more limited consideration of the detailed biology of the organisms. The preoccupation of demographic analysis with $r_{m}$ (which actually is seldom realized in the field for very long), and its focus on the importance of early individuals, contrasts with the more general question asked by many entomologists as to when individuals of a particular generation are present in a given stage and what is the average duration of development. Those more general questions usually are best answered by central (e.g. mean, 50\%) rather than firstoccurrence statistics, even though the latter are useful for the timing of insect control procedures in some instances (see also the discussion above under Temporal patterns).

In particular, as already pointed out for models of developmental rate, results expressed only as derived demographic statistics are unusable for the wider assessment of life-cycle duration. Presenting less derived data at the same time would retain helpful information that has been discovered about the biology of the organism. Such different demographic and general perspectives also influence the view of what constitutes optimum conditions for development.

\section{DIFFICULTIES WITH AVAILABLE DATA}

Many of the available data on life-cycle durations are inadequate for wider analysis. Such deficiencies stem from a wide range of difficulties in identifying and maintaining living material, and in experimental design and data analysis, as summarized in Table 1. Many of these cautions are applicable to scientific work of all kinds.

Status of material. The taxonomic status of the material must be properly known. Sometimes sibling species, with potentially different rates of development, have been confused under a single name. Wilkinson (1981) reported that whenever he had been called upon to assist physiologists unable to repeat earlier experiments, he found that either their animals or the original animals had been identified incorrectly. Voucher specimens for the experiments should therefore be kept. Even when the species is known, different strains may have particular thresholds and rates of development, which have been selected for in different geographical populations (Danks, 1987, p. 58; Honěk, 1996b; Ishihara, 1998).

Different forms of one species commonly show different responses, caused directly or by different reactions to environmental cues. For example, the morphs, colour forms, and even clones of aphids develop at different rates (Araya et al., 1996). Such clonal differences may lead to erroneous conclusions that there are geographical or population differences (Lamb et al., 1987). The preoviposition period differs between individuals with different dispersal capabilities (some examples are given above under Adult stage; see also Spence, 1989 and Socha \& Šula, 1998 for macropterous and brachypterous morphs of some heteropterans).

Durations of the substages of development can also change through inadvertent selection during laboratory rearing over a number of generations, producing a "laboratory strain". The incidence of diapause can be modified in most species (Danks, 1987, Table 30), but so too can intervals such as the duration of development (e.g. shorter in laboratory populations of the dermestid beetle Attagenus elongatulus Casey: Barak \& Burkholder, 1977) and the preoviposition period (e.g. shorter in a laboratory population of the tephritid fly Anastrepha suspensa (Loew): Kamasaki et al., 1970). Howe (1967) believed that some laboratory stocks were mixtures of more than one strain. Some cultures are maintained by selecting 
TABLE 1. Common experimental difficulties in work on life-cycle duration.

\begin{tabular}{|c|c|}
\hline Variable & Sample difficulties \\
\hline \multicolumn{2}{|l|}{ Status of material } \\
\hline Identification & $\begin{array}{l}\text { Sibling species are not distinguished; strain is not determined; voucher specimens are not } \\
\text { kept }\end{array}$ \\
\hline Laboratory selection & Laboratory rearing through several generations alters responses \\
\hline Infection & Sublethal pathogens are not detected but alter development \\
\hline Conditioning & $\begin{array}{l}\text { Experiments are conducted on material held previously in conditions that are not fully con- } \\
\text { trolled but affect the response }\end{array}$ \\
\hline \multicolumn{2}{|l|}{ Laboratory rearing } \\
\hline Rates of development & General rearing conditions (additional to the measured variables) distort responses \\
\hline Delays & $\begin{array}{l}\text { Unreported diapause results from particular conditions (e.g. low temperatures); suitable } \\
\text { pupation sites or materials are missing }\end{array}$ \\
\hline \multicolumn{2}{|l|}{ Experimental design } \\
\hline Replication & Sample sizes and replication are inadequate \\
\hline Definition and measurement of stages & $\begin{array}{l}\text { Stage of development is inadequately defined; more than one stage is included; hidden } \\
\text { stages are not observed and are included with another stage; data for too few stages or } \\
\text { substages are recorded }\end{array}$ \\
\hline Choice of conditions & $\begin{array}{l}\text { Range of conditions is too narrow or uneven; conditions are too close to unsuitable } \\
\text { extremes; a generally used standard condition is lacking }\end{array}$ \\
\hline Experimental procedure & $\begin{array}{l}\text { Development is modified by disturbance during observations; temperatures vary irregu- } \\
\text { larly; temperature chambers are not calibrated; stages are monitored too infrequently; } \\
\text { individuals are not equivalent }\end{array}$ \\
\hline Planning for analysis & $\begin{array}{l}\text { A programme of varying temperatures defeats analysis; results are inadequate for analysis } \\
\text { (see Replication, above) }\end{array}$ \\
\hline \multicolumn{2}{|l|}{ Analysis of results } \\
\hline Data presentation & $\begin{array}{l}\text { Results are only partially given; inappropriate groupings of data conceal responses; central } \\
\text { measures are emphasized, and meaningful variations or polymorphism disregarded as } \\
\text { "noise"; only derived summary statistics are given }\end{array}$ \\
\hline Summary statistics & $\begin{array}{l}\text { Choice of statistics is poor or too limited; derivation of the statistics given is not precisely } \\
\text { specified; variation is not adequately characterized }\end{array}$ \\
\hline Assumptions & $\begin{array}{l}\text { Temperature cannot be averaged arithmetically; many mathematical models contain sim- } \\
\text { plifying assumptions that limit their usefulness }\end{array}$ \\
\hline Context & Further biological information that would be helpful to interpret the results is not given \\
\hline Conclusions & $\begin{array}{l}\text { Summary statements or statistics are too complex to understand; summaries emphasize } \\
\text { only one aspect and are too simple; conclusions from data for one species are applied } \\
\text { incorrectly to others; comparisons do not take account of differences among stages or } \\
\text { conditions }\end{array}$ \\
\hline
\end{tabular}

adults from the early part of the emergence period or at a particular time of the week, to reduce labour or to accord with work schedules. Such procedures are likely to alter developmental and demographic parameters (cf. Bryant \& Reed, 1999). The rate of development in laboratory colonies can also be slowed by infection by sublethal pathogens (see Delays), as well as by the more visible attacks of nematodes and insect parasitoids.

Treatments received by the laboratory material before the actual experiment begins can influence the results. Apart from the life-cycle programming associated with diapause, such as delayed development in response to photoperiod, even the conditions in normal larval cultures may influence features of the oviposition period if they have not been carefully planned or controlled in the context of an experiment on adults. For example, even in standard mass cultures, crowding, number of instars or other factors potentially influencing size or stored food, and hence fecundity, vary from time to time or from one individual to the next. Previous conditioning, such as acclimation to particular temperatures, can alter responses. Of course, stresses of various kinds, such as cold shocks, are likely to reduce subsequent developmental or reproductive rates or longevity (Abukashim \& Luff, 1997; McDonald et al., 1997).

Laboratory rearing. Because most aspects of field environments cannot be controlled or even measured, accurate data on substage durations relies on laboratory rearing. However, rearing or maintaining some species of living animals is difficult, because not all of their particular needs can be met precisely. An experimental variable such as temperature may then have been carefully controlled, but other less obvious variables were not, influencing rates of development. Such variables include especially food quality but also photoperiod, humidity, and degree of crowding [Cheke, 1995 for the noctuid 
moth Spodoptera exempta (Walker)]. Some species of parasitoids take longer to develop in larger than in smaller hosts (Jonasson et al., 1995 for Aleochara spp.). Many laboratory cultures rely on artificial diets, usually designed to provide optimal nutritional requirements, but they may alter developmental rate, longevity and fecundity relative to normal field or other conditions (see Delays and programmes, above, for additional information on conditions that limit growth).

Development stops in some or all of the experimental animals if conditions induce diapause, and delays also result from the absence of specific requirements other than food, such as pupation or pupariation sites that are of suitable shape or moisture content, substrates for the construction of pupal chambers, or materials for incorporation into cocoons.

Requirements for mating are exacting in many species, and delayed mating normally lengthens the preoviposition period or changes the later pattern of oviposition [Leather et al., 1985 for the noctuid moth Panolis flammea (D. \& S.)]. Lack of mating may decrease longevity (Kazimírová, 1996 for the noctuid moth Mamestra brassicae L.), or increase longevity but decrease fecundity, for example [Vickers, 1997 for the tortricid moth Cydia pomonella (L.)]. Multiple matings enhance fecundity in the pyralid moth Ostrinia nubilalis (Hübner) (Fadamiro \& Baker, 1999). The longevity and oviposition period of the blow fly Chrysomya albiceps (Wiedemann) depends on the sex ratio in culture cages (Queiroz et al., 1996). Cage size and date of emergence influence longevity in the agromyzid fly Liriomyza trifolii (Burgess) (Heinz, 1996). Moisture content in the oviposition medium (sawdust) for the chafer Anomala cuprea (Hope) affects preoviposition and oviposition periods, fecundity and longevity (Bhuiyan \& Nishigaki, 1997). Sperm depletion (which depends on mating history) influences oviposition patterns in the alydid bug Riptortus clavatus Thunberg (Sakurai, 1998). However, some species can partly compensate for early delays: longevity and fertility (but not fecundity) of the pyralid moth Eoruma loftini (Dyar) is hardly affected by delays in mating of up to 5 days (Spurgeon et al., 1997).

Adult food supplies greatly modify longevity, as well as the rates and patterns of oviposition, in species that rely on adult feeding for flight energy or egg development. For example, longevity and whether or not oviposition takes place depends on the availability of water, plants and prey in the pentatomid bug Podisus maculiventris (Say) (Valicente \& O'Neil, 1995). Measures of adult longevity or patterns of oviposition therefore are not informative if the conditions used unusually abbreviate or prolong adult life. Sugar meals are required for flight energy (and normal longevity) by many adults (e.g. Waldbauer et al., 1980). Culex pipiens L. mosquitoes survived up to 3 weeks unfed, 6 weeks on sugar solution, and 14 weeks on sugar and blood (Almiron \& Brewer, 1996). Many moths and flies survive only a short time in dry conditions without sugar meals. Conversely, parasitoids such as ichneumonids and tachinids that are kept in relatively dully lighted environments or deprived of hosts will live a very long time without ovipositing at normal rates (Danks, 1975; pers. obs.). Because each species is different, ensuring that results are not influenced by more subtle effects requires detailed knowledge of adult requirements for the particular species. This knowledge can be acquired chiefly through simple but well organized preliminary experiments to evaluate responses to a range of general rearing conditions of light, temperature, humidity, available space and crowding, protein and carbohydrate foods, water and mating. Reduced fecundity or longevity compared with other regimens signals an inadequate condition. Several sets of published data on longevity of the same species at the same temperature diverge widely from one another because other conditions important to the wellbeing of adults were not controlled.

Experimental design. Even the most basic experimental procedures have to be carefully thought out, because even the handling required to make observations can alter developmental rates, as in larvae of the blow fly Phaenicia pallescens (Shannon) (Ash \& Greenberg, 1975).

Adequate numbers of individuals are required for each treatment to reduce the effect of random deviations. For example, one individual taking an extra few days in a sample of eight changes the mean by half a day; the same individual in a sample of 100 (a suitable number for experimental treatments) changes the mean by a negligible amount. Knowing the approximate mean duration for a stage (derived from preliminary experiments or published data) allows a target standard deviation to be estimated from the regression calculated by Schaffer (1983) $[\mathrm{SD}=0.209 \overline{\mathrm{x}}]$, which in turn can be used to indicate a suitable sample size (see Schaffer, 1983). Correspondingly, data can only be evaluated if sample sizes and standard deviations are published, as emphasized under Analysis of results, below.

Adequate replication of experimental treatments allows statistical analysis. The individuals in one container are not generally suitable as "replicates", because they do not allow the variance of subsamples (i.e. multiple sets of an adequate number of individuals) to be compared. Similarly, multiple treatments are desirable, because more extensive data disqualify incorrect theories.

Comparisons among species rely on consistent definitions and reporting of the stages being measured (recommendations are summarized in the conclusions). Difficulties arise especially from arbitrary definitions of such periods as "peak oviposition" (e.g. the day on which the most eggs are laid, or the interval of highest egg production) and from data provided only on combined stages. Although only combined data can be collected for some species (see Hidden stages), combinations (e.g. egg plus larva) not only obscure stage relationships, but also have caused data for different intervals to be given the same label. For example, resting stages may or may not be included with the preceding instars. Data for the prepupal stage may be given separately from the larval stage, combined with it, or even combined with the pupal stage. The teneral period spent in the cocoon by some Coleoptera 
TABLE 2. Recommended background information to be reported on material used in experiments on life-cycle duration.

\begin{tabular}{ll}
\hline Recommended information to be given & Notes \\
\hline Species & Basis of validation except in the best known species, including whereabouts of vouchers \\
Strain & Origin, from field (locality, season) or laboratory (rearing history) \\
Previous conditioning & All details of rearing conditions (not just temperature), including food, humidity, etc. \\
Temporal or serial placement & Field generation, non-diapause treatment, etc. \\
Number of instars in each treatment & If variation in instar numbers is known in the species \\
General biology & Natural habitat, normal life cycle, known developmental delays, etc. \\
Taxonomic patterns & Any developmental patterns characteristic of the taxon, or departures from them, if \\
& known (e.g. unusually short-lived adults) \\
\hline
\end{tabular}

and Hymenoptera is given separately by some authors. It has also been included with the pupal period, or with the adult period, and some authors have not recorded which of these alternatives (based on eclosion or on emergence) was used.

Different intervals in immature development have been given the same name by some authors. Imprecise terms such as "egg to adult" should either be avoided or clearly defined. For example, this term has been used to mean oviposition to adult eclosion and oviposition to emergence, as well as egg hatch to adult eclosion or emergence.

Much published work is restricted to one or a few stages (e.g. immature development only, larval development only, or adult longevity and fecundity only). Because it is very difficult to ensure that the strains and conditions are identical for different experiments, work on only part of the life-cycle often cannot be extrapolated successfully to the life cycle as a whole.

For most purposes, the conditions chosen for experiments on life-cycle duration should lie near the middle of the suitable range, because effects at the extremes (unless these are the object of the study) give misleading information about developmental rates, and also may be ecologically irrelevant. The most useful data for subsequent general analyses cover a range of appropriate conditions that are more or less evenly spaced. Howe (1967) recommended using 10 temperatures not more than 2.5 Centigrade degrees apart, and he also called for additional intervals of 0.5 or 1 degree for 3 degrees either side of the optimum and of the limits. Relatively few studies have adopted even the 2.5 or 3 degree $C$ interval thought by Howe (1967) and Liu et al. (1995) to be appropriate. [Pruess (1983) recommended the adoption of $5^{\circ} \mathrm{C}, 10^{\circ} \mathrm{C}$ and $15^{\circ} \mathrm{C}$ as standard thresholds for calculating temperature sums.] Adopting standard conditions of $20^{\circ} \mathrm{C}$ and $25^{\circ} \mathrm{C}$ (in addition to any other particular conditions used) would be especially valuable for comparing life-cycle duration. Comparison is easier when temperatures are in whole Celsius degrees, not conversions from the Fahrenheit equipment still often used in the United States.

The details of experimental procedures must be established and followed with care. For example, it is necessary to ensure that temperature settings are exact by checking and recalibrating experimental chambers regularly, independent of built-in thermometers or controllers. Moreover, deviation in readily available equipment com- monly is $\pm 1^{\circ} \mathrm{C}$, a range that is too wide for some purposes. Hygrothermographs are especially useful for continuously monitoring temperature and humidity in each chamber, to ensure that the mean temperature is accurate and to verify the deviation allowed by the controller. However, such monitoring devices must be in the location of the insects and so within the container housing them. Chamber lights can cause local heating, for example; glass vessels can damp variations in incubator temperature by up to $2^{\circ} \mathrm{C}$ (Howe, 1967). Insects also modify the temperatures they experience. For example, body orientation by grasshoppers elevates their temperature even in the laboratory (Lactin \& Johnson, 1996a, b). Such behaviours in the field can increase the day-degrees available to an insect many fold, as modelled by Bryant et al. (1998).

Especially in stages or species that develop rapidly at higher temperatures, such as some eggs, and some mites, aphids and flies, daily recording of stages is too infrequent to generate accurate data. Monitoring hourly or still more frequently may even be necessary (e.g. Ryan, 1962; Lykouressis, 1985; Greenberg \& Tantawi, 1993). Indeed, the observation interval should be adjusted to the developmental interval to avoid imprecise data and inequalities of variance among treatments. Schaffer (1983) pointed out that many published data for insect eggs have $\mathrm{SD}=0$ because all eggs hatched during a single period of observation! He noted that a suitable interval for observation is less than one standard deviation. (Such an interval would provide at least 6 observations across the total duration.)

Many studies of immature development initiate experiments with eggs from a short period of oviposition by confined adults taken from a stock culture. Such adults are of variable or unknown age, and in some species the quality of offspring varies with the age of the mother.

Analysis of results. Normally, data are best presented as completely and in as untransformed a manner as possible for the particular objective, because such general results can be used for many wider purposes. Both total and substage duration should be summarized (see Total and component intervals). Wider use of results is compromised if only highly derived measures or graphical summaries, such as demographic indexes or small-scale plots of oviposition over time, are presented. Unless core data are also given, measures such as biomass doubling time, percentage development per day, and percent length per 
TABLE 3. Recommended terminology and key intervals for defining and measuring the duration of life-cycle stages in an individual (compare also Figs 1, 2).

\begin{tabular}{ll}
\hline $\begin{array}{l}\text { Recommended terms for stages } \\
\text { and intervals to measure }\end{array}$ & Notes (and additional terms) \\
\hline Immature stages & $\begin{array}{l}\text { Oviposition until adult eclosion } \\
\text { (Premoult periods are included as part of a stage) } \\
\text { Oviposition until hatch }\end{array}$ \\
Lag & $\begin{array}{l}\text { Hatch until pupation (i.e. the period up to pupal ecdysis, includes the prepupal stage). When } \\
\text { pupation is hidden, use e.g. pupariation, not "pupation". Record total larval period even if }\end{array}$ \\
& instars are also recorded separately; for the latter use numbered instars 1 to $\mathrm{n}$ \\
Prepupa & End of larval feeding until pupation \\
Pupa & Pupation to adult eclosion \\
Adult stage & Adult eclosion to death (=longevity) \\
Teneral & Eclosion until full cuticular sclerotization \\
(Emergence) & (Eclosion until adult visible and active) \\
Premating & Eclosion until the start of (first) mating (The duration of mating itself is very short in most spe- \\
cies) & Eclosion until the first egg is deposited \\
Preoviposition & First egg until last egg \\
Oviposition & Eclosion until last egg \\
(Reproductive life) &
\end{tabular}

day — used by some authors — are also difficult to interpret.

The differences among individuals in a given treatment are of both biological and statistical interest, and can be expressed in well known ways such as the range and the standard deviation. Care is required when data are not normally distributed. Deviations from normality can of course be produced by sample sizes that are too small as well as from non-normality of the underlying distribution. Comparisons among different treatments (e.g. fluctuating vs. constant temperatures) require statistical tests such as analysis of variance to determine whether differences among the treatment means are significant. Such analyses for data that are not normally distributed first require transformations to normalize the data and homogenize the variance. Examining the statistical distribution of the untransformed data therefore is a very helpful way to decide how to present summary data and measures of variation.

Care must be taken to specify the numbers of individuals and error terms for each data point. For example, if mortality occurs during a stage, the number of survivors on which the mean duration is based, and not just the standard starting number for each experimental treatment, must be given (Schaffer, 1983). Statistical tests can also illuminate certain biological claims. For example, the greater variance of developmental time at low temperatures, when the mean duration of development is very long, may reflect simply the statistical correlation between mean and variance (e.g. Lamb \& Loschiavo, 1981; Schaffer, 1983) rather than the disturbance of development in marginal conditions or any other biologically significant possibility.

In summary, a confirmation of normality, and the sample size and estimate(s) of experimental error for each data point should be explained in the methods and made available for reference (cf. Eisenhart, 1968).

The grouping of data to assist analysis may obscure information of interest. Sexual differences have already been noted. When the duration of a stage forms a continuum from "normal" to "delayed" development, typically it would be separated more or less arbitrarily into two discrete categories for analysis. Grouping of data may obscure patterns of variation, and also results that do not belong to a well defined group or that are unusual may be explained away or even discarded. For example, extreme variants are often discounted as experimental noise or concealed in heterogenous groupings ("longer than..."), despite their potential adaptive value in providing insurance against unpredictable natural conditions (Danks, 1983b).

Statistics used to summarize results may be too narrowly focussed, or diverge unnecessarily from more standard forms of presentation. Some of the derived statistics for demography and development, especially those based on mathematical models, rely on assumptions or approximations that are not necessarily valid. As already noted, actual durations should be given as well as the measures such as $T_{0}, K, r_{m}$ and $R_{0}$ derived from them. Such brief tabulations take little extra space.

One great difficulty in summarizing whole life cycles stems from the need to estimate conditions in which 
TABLE 4. Recommended numerical and statistical information about the duration of life-cycle stages to be reported in addition to any derived statistics or graphical summaries required for particular purposes.

\begin{tabular}{|c|c|}
\hline Recommended measures & Stages to be applied to; other measures \\
\hline \multicolumn{2}{|l|}{ Durations } \\
\hline $50 \%$ population measures & $\begin{array}{l}\text { Egg development, larval development, pupal development, longevity, number of } \\
\text { eggs laid; also range }\end{array}$ \\
\hline (10\% population measures & See discussion under Temporal patterns) \\
\hline Population means of start and end & Oviposition; also first and last individual records, and range \\
\hline \multicolumn{2}{|l|}{ Distributions } \\
\hline Type of distribution if other than normal & All durations \\
\hline $\begin{array}{l}\text { Temporal pattern for population, as well as } \\
\text { (not instead of) statistics on mean duration }\end{array}$ & Oviposition \\
\hline $\begin{array}{l}\text { Cumulative percentages, including } 10 \% \text {, } \\
50 \% \text { and } 90 \%\end{array}$ & $\begin{array}{l}\text { Key distributions; see Fig. } 3 \text { [characterizing the distribution of oviposition with } 0 \text {, } \\
10,50,90 \text { and } 100 \% \text { markers is usually preferable to dates of "maximum oviposi- } \\
\text { tion" based on peak day (susceptible to experimental noise) or peak period } \\
\text { (potentially subjective)] }\end{array}$ \\
\hline \multicolumn{2}{|l|}{ Variation } \\
\hline $\begin{array}{l}\text { Adequate characterization (normality, } \\
\text { sample size, and error term as a minimum) }\end{array}$ & All treatments \\
\hline $\begin{array}{l}\text { Changes in quality of individuals (e.g. sex } \\
\text { ratio) }\end{array}$ & All affected durations \\
\hline
\end{tabular}

growth or development, or some measure of reproductive potential, is optimal. The "best" temperature among a small number of divergent temperatures may be obvious, because all of the relevant measures, such as biomass (dry weight), growth rate of every stage, survival and fecundity are maximized at one of the temperatures. Commonly, however, some parameters (such as offspring quality and rate of oviposition) change through the measured interval, and in particular different temperatures affect the parameters differently. Indeed, because tradeoffs between the duration of development and size, size and survival, size and fecundity, fecundity and longevity, and so on occur in most species (Danks, 1994), the effect of changes on demographic parameters such as the rate of increase is not simple.

For example, development at all stages of the gelechiid moth Pectinophora gossypiella (Saunders) is faster at $32^{\circ} \mathrm{C}$ than at $26^{\circ} \mathrm{C}$, but survival and fecundity are much greater at the lower temperature (Raina et al., 1977). Similar differences between the temperature at which survival and development is greatest occur in many species [e.g. Guppy \& Harcourt, 1978 for the chrysomelid beetle Oulema melanopus (L.)]; reproductive rate is higher for those that survive at the higher temperature, but not necessarily for the population as a whole. Analysis for the pteromalid parasitoid Catolaccus grandis (Burks) (Morales-Ramos et al., 1996) showed that development was shortest at $30^{\circ} \mathrm{C}(67 \%$ R.H. $)$, fecundity was greatest at $26^{\circ} \mathrm{C}(68 \%$ R.H. $), \mathrm{R}_{0}$ at $27^{\circ} \mathrm{C}(63 \%$ R.H. $)$ and $\mathrm{r}_{\mathrm{m}}$ at $29^{\circ} \mathrm{C}(66 \%$ R.H.). In other words, the response of the various measures of duration and success to different conditions is not concordant, and each of them has a different effect on demographic estimators of fitness. Therefore, any single set of conditions may well be "optimal" for only a single stage of development. In any event, providing full details of several "fitness" measures under several conditions will support attempts to refine our current preliminary definition of the optimum.

As a result of these complexities, especially differences among different species in the number of visible stages and other aspects of biology, and even different responses by a single species during different parts of the life cycle, conclusions and comparisons may be unintelligible, misleading, or overgeneralized. Many of these problems can be overcome, and data made more widely available, by ensuring that experiments are carefully planned from a broad perspective, and that data and statistics are presented as clearly and simply as possible.

\section{CONCLUSIONS}

Many factors influence the duration of insect life cycles. Understanding them requires detailed knowledge of the biology of individual species, despite a current tendency toward summary and modelling in a narrow context. By the same token, developmental responses are complex, so that consistent presentation of several descriptors and statistical measures of life-cycle duration is desirable.

The information reviewed in previous sections has been summarized in the form of three sets of recommendations on how studies should be conducted and published information should be standardized whenever possible. Table 2 recommends the background information that should be included in papers on life-cycle duration to provide the proper context for interpreting and using the results. Table 3 recommends consistent terminology and choice of intervals for measuring and reporting durations. Table 4 recommends the ways in which numerical information should be reported. I hope that these checklists, together with the detailed cautions about methodology given in Table 1, will serve as a reminder of the great complexity of insect life cycles and responses, and will help to ensure 
that results are valid, and that published data are more broadly useful for analyzing the developmental rates and routes that are the basis of life-cycle adaptation.

ACKNOWLEDGEMENTS. I am very grateful to L.M. Dosdall (Alberta Agriculture, Edmonton), R.J. Lamb (Agriculture and Agri-Food Canada, Winnipeg) and an anonymous reviewer for a variety of helpful comments on the manuscript.

\section{REFERENCES}

Abou-Setta M.M. \& ChILders C.C. 1991: Intrinsic rate of increase over different generation time intervals of insect and mite species with overlapping generations. Ann. Entomol. Soc. Am. 84: 517-521.

AвUKHAshim N.K. \& LUfF M.L. 1997: Effects of short exposure periods to low temperatures on the biology of Tetranychus urticae. Acarologia 38: 255-263.

Almiron W.R. \& Brewer M.E. 1996: Winter biology of Culex pipiens quinquefasciatus Say, (Diptera: Culicidae) from Cordoba, Argentina. Mem. Inst. Oswaldo Cruz 91: 649-654.

Applebaum S.W. \& Herfetz Y. 1999: Density-dependent physiological phase in insects. Annu. Rev. Entomol. 44: 317-341.

Araya J.E., Cambron S.E. \& Ratcliffe R.H. 1996: Development and reproduction of two color forms of English grain aphid (Homoptera: Aphididae). Envir. Entomol. 25: 366-369.

Arbogast R.T. 1984: Demography of the predaceous bug Dufouriellus ater (Hemiptera: Anthocoridae). Envir. Entomol. 13: 990-994.

Asm N. \& Greenberg B. 1975: Developmental temperature responses of the sibling species Phaenicia sericata and $\mathrm{P}$. pallescens. Ann. Entomol. Soc. Am. 68: 197-200.

AYres M.P. \& MACLEAN S.F. JR. 1987: Molt as a component of insect development: Galerucella sagittariae (Chrysomelidae) and Epirrita autumnata (Geometridae). Oikos 48: 273-279.

BaraK A.V. \& Burkholder W.E. 1977: Studies on the biology of Attagenus elongatulus Casey (Coleoptera: Dermestidae) and the effects of larval crowding on pupation and life cycle. J. Stored Prod. Res. 13: 169-175.

BaUer L.S. \& Nordin G.L. 1988: Pathogenicity of Nosema fumiferanae (Thomson) (Microsporida) in spruce budworm, Choristoneura fumiferana (Clemens), and implications of diapause conditions. Can. Entomol. 120: 221-229.

Baumann R.W. 1987: Order Plecoptera. In Stehr F.W. (ed.) Immature Insects. Kendall/Hunt, Dubuque, pp. 186-195.

BECK S.D. 1971: Growth and retrogression in larvae of Trogoderma glabrum (Coleoptera: Dermestidae). I. Characteristics under feeding and starvation conditions. Ann. Entomol. Soc. Am. 64: 149-155.

BhưYAN M.K.R. \& NishigaKI J. 1997: Oviposition of the adult cupreous chafer, Anomala cuprea Hope (Coleoptera: Scarabaeidae), at different water contents of the ovipositing medium under laboratory conditions. Appl. Entomol. Zool. 32: 431-436.

BrRCH L.C. 1948: The intrinsic rate of natural increase of an insect population. J. Anim. Ecol. 17: 15-26.

BRABY M.F. \& Jones R.E. 1995: Reproductive patterns and resource allocation in tropical butterflies: influence of adult diet and seasonal phenotype on fecundity, longevity and egg size. Oikos 72: 189-204.

Bradshaw W.E. \& Holzapfel C.M. 1992: Reproductive consequences of density-dependent size variation in the pitcherplant mosquito, Wyeomyia smithii (Diptera: Culicidae). Ann. Entomol. Soc. Am. 85: 274-281.

Braman S.K. \& YeARGAN K.V. 1988: Comparison of developmental and reproductive rates of Nabis americoferus, $\mathrm{N}$. roseipennis, and N. rufusculus (Hemiptera: Nabidae). Ann. Entomol. Soc. Am. 81: 923-930.

Briere J.-F. \& Pracros P. 1998: Comparison of temperaturedependent growth models with the development of Lobesia botrana (Lepidoptera: Tortricidae). Envir. Entomol. 27: 94-101.

BritTAIN J.E. 1976: Experimental studies on nymphal growth in Leptophlebia vespertina (L.) (Ephemeroptera). Freshwat. Biol. 6: 445-449.

Brittain J.E. 1982: Biology of mayflies. Annu. Rev. Entomol. 27: 119-147.

BuCKINGHAM G.R. \& BENNETT C.A. 1981: Laboratory biology and behavior of Litodactylus leucogaster, a ceuthorhynchine weevil that feeds on watermilfoils. Ann. Entomol. Soc. Am. 74: 451-458.

Bryant E.H. \& Reed D.H. 1999: Fitness decline under relaxed selection in captive populations. Conserv. Biol. 13: 665-669.

Bryant S.R., Bale J.S. \& Thomas C.D. 1998: Modification of the triangle method of degree-day accumulation to allow for behavioural thermoregulation in insects. J. Anim. Ecol. 35: 921-927.

CAREY J.R. 1993: Applied Demography for Biologists with Special Emphasis on Insects. Oxford University Press, New York, $206 \mathrm{pp}$.

Care J.R., Liedo P., Mueller H.-G., Wang J.-L. \& Vaupel J.W. 1998: Dual modes of aging in Mediterranean fruit fly females. Science (Washington) 281: 996-998.

Carlsson G. 1962: Studies on Scandinavian blackflies. Opusc. Entomol. Suppl. 21. $280 \mathrm{pp}$.

CheKe R.A. 1995: Potential rates of increase of solitarious and gregarious phases of the African armyworm Spodoptera exempta (Lepidoptera: Noctuidae). Ecol. Entomol. 20: 319-325.

Clare G.K. \& Singh P. 1990: Variation in the number of larval instars of the brownheaded leafroller, Ctenopneustis obliquana (Lepidoptera: Tortricidae) at constant laboratory temperatures. N. Z. J. Zool. 17: 141-146.

ClifFord H.F. 1982: Life cycles of mayflies (Ephemeroptera), with special reference to voltinism. Quaest. Entomol. 18: $15-89$.

Clifford H.F., Hamilton H. \& Killins B.A. 1979: Biology of the mayfly Leptophlebia cupida Say (Ephemeroptera: Leptophlebiidae). Can. J. Zool. 57: 1026-1045.

Collins R.D. \& Grafius E. 1986: Biology and life cycle of Anaphes sordidatus (Hymenoptera: Mymaridae), an egg parasitoid of the carrot weevil (Coleoptera: Curculionidae). Envir. Entomol. 15: 100-105.

CoRbet P.S. \& DANKs H.V. 1973: Seasonal emergence and activity of mosquitoes in a high arctic locality. Can. Entomol. 105: 837-872.

CoRnell H.V. 1990: Survivorship, life history, and concealment: a comparison of leaf miners and gall formers. Am. Nat. 136: 581-597.

CRANFORD J. 1972: The Microsporidian Nosema heliothidis Lutz and Splendor as a Parasite of Heliothis zea (Boddie) and Heliothis virescens $(F$.). Unpubl. MSc. thesis, North Carolina State University, Raleigh.

Crill W.D., Hutey R.B. \& Gilchrist G.W. 1996: Within- and between-generation effects of temperature on the morphology and physiology of Drosophila melanogaster. Evolution 50: $1205-1218$.

CRonin J.T. \& STRONG D.R. 1990: Biology of Anagrus delicatus (Hymenoptera: Mymaridae), an egg parasitoid of Prokelisia marginata (Homoptera: Delphacidae). Ann. Entomol. Soc. Am. 83: 846-854. 
DanKs H.V. 1970: Biology of some stem-nesting aculeate Hymenoptera. Trans. R. Entomol. Soc. Lond. 122: 323-395.

DANKS H.V. 1971: Life history and biology of Einfeldia synchrona (Diptera: Chironomidae). Can. Entomol. 103: 1597-1606.

DanKs H.V. 1975: Factors determining levels of parasitism by Winthemia rufopicta (Diptera: Tachinidae), with particular reference to Heliothis spp. (Lepidoptera: Noctuidae) as hosts. Can. Entomol. 107: 655-684.

DANKs H.V. 1983a: Differences between generations in the sex ratio of aculeate Hymenoptera. Evolution 37: 414-416.

DANks H.V. 1983b: Extreme individuals in natural populations. Bull. Entomol. Soc. Am. 29: 41-46.

DANKS H.V. 1987: Insect Dormancy: An Ecological Perspective. Biological Survey of Canada (Terrestrial Arthropods), Ottawa, $439 \mathrm{pp}$.

DANKS H.V. 1991: Life-cycle pathways and the analysis of complex life cycles in insects. Can. Entomol. 123: 23-40.

DANKS H.V. 1992: Long life cycles in insects. Can. Entomol. 124: $167-187$.

DANKS H.V. 1994: Diversity and integration of life-cycle controls in insects. In Danks H.V. (ed.): Insect Life-cycle Polymorphism: Theory, Evolution and Ecological Consequences for Seasonality and Diapause Control. Kluwer Academic Publishers, Dordrecht, pp. 5-40.

DANKS H.V. \& OLIVER D.R. 1972: Seasonal emergence of some high arctic Chironomidae (Diptera). Can. Entomol. 104: 661-686.

Danthanarayana W., Gu H. \& Ashley S. 1995: Population growth potential of Epiphyas postvittana, the lightbrown apple moth (Lepidoptera: Tortricidae) in relation to diet, temperature and climate. Austr. J. Zool. 43: 381-394.

DAUTel H. \& KNüLle W. 1997: Life cycle and seasonal development of post-embryonic Argas reflexus (Acari: Argasidae) at two thermally different locations in Central Europe. Exp. Appl. Acarol. 21: 697-712.

DAvidson J. 1944: On the relationship between temperature and rate of development of insects at constant temperatures. $J$. Anim. Ecol. 13: 26-38.

Davies B.R. 1976: The dispersal of chironomid larvae: a review. J. Entomol. Soc. Sth. Afr. 39: 39-62.

DeAngelis J.D., Sether J.M. \& Rossignol P.A. 1993: Survival, development, and reproduction in western flower thrips (Thysanoptera: Thripidae) exposed to impatiens necrotic spot virus. Envir. Entomol. 22: 1308-1312.

Delucchi C.M. \& PeCKARSKy B.L. 1989: Life history patterns of insects in an intermittent and a permanent stream. $J . N . A m$. Benthol. Soc. 8: 308-321.

DETLAFF T.A. 1996: [Comparison of the duration of various periods of embryogenesis $\left(t_{n}\right)$ in representatives of eight insect orders with the help of relative criteria of biological time $\left(\mathrm{t}_{\mathrm{n}}-\mathrm{t}_{0}\right)$ ]. Ontogenez 27: 427-433 (in Russian)

Dingle H. 1972: Migration strategies of insects. Science (Washington) 175: 1327-1335.

Dosdall L.M. \& Lemmkuml D.M. 1979: Stoneflies (Plecoptera) of Saskatchewan. Quaest. Entomol. 15: 3-1 16.

Draye X. \& LinTS F.A. 1996: Geographic variations of life history strategies in Drosophila melanogaster III. New data. Exp. Gerontol. 31: 717-733.

Dublin L.I. \& LotKA A.J. 1925: On the true rate of natural increase. J. Am. Statistics Assoc. 20: 305-339.

ELLSBURY M.M. 1991: Development of the immature stages of the clover stem borer (Coleoptera: Languriidae) at constant temperatures. Envir. Entomol. 20: 1181-1186.
EISENHART C. 1968: Expression of the uncertainties of final results. Science (Washington) 160: 1201-1204.

FADAMIRO H.Y. \& BAKER T.C. 1999: Reproductive performance and longevity of female European corn borer, Ostrinia nubilalis: effects of multiple mating, delay in mating, and adult feeding. J. Insect Physiol. 45: 385-392.

FinK T.J. 1980: A comparison of mayfly (Ephemeroptera) instar determination methods. In Flannagan J.F. \& Marshall K.E. (eds): Advances in Ephemeroptera Biology (Proc. 3rd Int. Conf. Ephemeroptera), pp. 367-380.

Gerard P.J. \& RuF L.D. 1997: Development and biology of the immature stages of Anthrenocerus australis Hope (Coleoptera: Dermestidae). J. Stored Prod. Res. 33: 347-357.

Gotoh T., Kamota T., Hatakeyama M. \& Gomi K. 1994 Embryonic development and diapause stage in Panonychus mites (Acari: Tetranychidae). Appl. Entomol. Zool. 29: $507-515$.

Greenberg B. \& Tantawi T.I. 1993: Different developmental strategies in two boreal blow flies (Diptera: Calliphoridae). $J$. Med. Entomol. 30: 481-484.

GuPpY J.C. \& HaRCOURT D.G. 1978: Effects of temperature on development of the immature stages of the cereal leaf beetle, Oulema melanopus (Coleoptera: Chrysomelidae). Can. Entomol. 110: 257-263.

Hackett D.S. \& Gatehouse A.G. 1982: Diapause in Heliothis armigera (Hübner) and H. fletcheri (Hardwick) (Lepidoptera: Noctuidae) in the Sudan Gezira. Bull. Entomol. Res. 72: 409-422.

Hagstrum D.W. \& Milliken G.A. 1988: Quantitative analysis of temperature, moisture, and diet factors affecting insect development. Ann. Entomol. Soc. Am. 81: 539-546.

HARVEY G.T. 1957: The occurrence and nature of diapause-free development in the spruce budworm, Choristoneura fumiferana (Clem.) (Lepidoptera: Tortricidae). Can. J. Zool. 35: 549-572.

Hernz K.M. 1996: Space- and cohort-dependent longevity in adult Liriomyza trifolii (Burgess) (Diptera: Agromyzidae) mass-rearing cultures. Can. Entomol. 128: 1225-1237.

HILBERT D.W. 1995: Growth-based approach to modeling the developmental rate of arthropods. Envir. Entomol. 24: $771-778$.

Hilbert D.W. \& Logan J.A. 1983: Empirical model of nymphal development for the migratory grasshopper, Melanoplus sanguinipes (Orthoptera: Acrididae). Envir. Entomol. 12: 1-5.

Holbrook G.L. \& Schal C. 1998: Social influences on nymphal development in the cockroach, Diploptera punctata. Physiol. Entomol. 23: $121-130$.

HoNĚK A. 1996a: The relationship between thermal constants for insect development: a verification. Acta Soc. Zool. Bohemoslov. 60: 115-152.

HoNĚK A. 1996b: Geographical variation in thermal requirements for insect development. Eur. J. Entomol. 93: 303-312.

HONEKK A. 1997: Incidence of protogynous and protandrous development in the pre-imaginal stage of insect development: an overview. Acta Soc. Zool. Bohemoslov. 61: 113-128.

HoNĚK A. \& KOCOUREK F. 1990: Temperature and development time in insects: a general relationship between thermal constants. Zool. Jb.(Syst. Geogr. Biol. Tiere) 117: 401-439.

Howe R.W. 1962: The influence of diapause on the status as pests of insects found in houses and warehouses. Ann. Appl. Biol. 50: 611-614.

Howe R.W. 1967: Temperature effects on embryonic development in insects. Annu. Rev. Entomol. 12: 15-42.

Hulting F.L., ORR D.B. \& OBRYCKI J.J. 1990: A computer program for calculation and statistical comparison of intrinsic 
rates of increase and associated life table parameters. Fla Entomol. 73: 601-612.

INGRISCH S. 1984: Embryonic development of Decticus verrucivorus (Orthoptera: Tettigoniidae). Entomol. Gen. 10: 1-19.

IsHIHARA M. 1998: Geographical variation in insect developmental period: Effect of host plant phenology on the life cycle of the bruchid seed feeder Kytorhinus sharpianus. Entomol. Exp. Appl. 87: 311-319.

JACKSON J.J. \& ElLIOTT N.C. 1988: Temperature-dependent development of immature stages of the western corn rootworm, Diabrotica virgifera virgifera (Coleoptera: Chrysomelidae). Envir. Entomol. 17: 166-171.

Jornson C.G. 1969: Migration and Dispersal of Insects by Flight. Methuen, London, $763 \mathrm{pp}$.

Jonasson T., AHLström-Olsson M. \& Johansen T.J. 1995: Aleochara suffusa and A. bilineata (Col.: Staphylinidae) as parasitoids of brassica root flies in northern Norway. Entomophaga 40: $163-167$.

Kamasaki H., Sutton R., Fernando Lopez D. \& Selmime A. 1970: Laboratory culture of the Caribbean fruit fly, Anastrepha suspensa, in Florida. Ann. Entomol. Soc. Am. 63: 639-642.

KAMATA N. \& IgaRAshi M. 1995: Relationship between temperature, number of instars, larval growth, body size, and adult fecundity of Quadricalcarifera punctatella (Lepidoptera: Notodontidae): cost-benefit relationship. Envir. Entomol. 24: 648-656.

KAWANO S. \& ANDO Y. 1997: Effects of photoperiod on nymphal development, pre-oviposition period and egg diapause in the subtropical rice grasshopper, Oxya chinensis formosana Shiraki (Orthoptera: Catantopidae). Appl. Entomol. Zool. 32: 465-470.

KAzIMÍRová M. 1996: Influence of larval crowding and mating on lifespan and fecundity of Mamestra brassicae (Lepidoptera: Noctuidae). Eur. J. Entomol. 93: 45-52.

Kotaki T., Nakakita H. \& Kuwahara M. 1993: Crowding inhibits pupation in Tribolium freemani (Coleoptera: Tenebrionidae): Effects of isolation and juvenile hormone analogues on development and pupation. Appl. Entomol. Zool. 28: $43-52$.

Kusters G.J. \& Herrebout W.M. 1989: Non-dissective pupal indicators of diapause commitment in the small ermine moth of Orpine, Yponomeuta vigintipunctatus. Neth. J. Zool. 38: 132-142.

Lactin D.J., Holliday N.J., Johnson D.L. \& Craigen R. 1995 Improved rate model of temperature-dependent development by arthropods. Envir. Entomol. 24: 68-75.

LACTIN D.J. \& JoHNSON D.L. 1996a: Behavioural optimization of body temperature by nymphal grasshoppers (Melanoplus sanguinipes, Orthoptera: Acrididae) in temperature gradients established using incandescent bulbs. J. Therm. Biol. 21: 231-238

LACTIN D.J. \& Johnson D.L. 1996b: Effects of insolation and body orientation on internal thoracic temperature of nymphal Melanoplus packardii (Orthoptera: Acrididae). Envir. Entomol. 25: 423-429.

LAMB R.J. 1992: Developmental rate of Acyrthosiphon pisum (Homoptera: Aphididae) at low temperatures: implications for estimating rate parameters for insects. Envir. Entomol. 21: $10-19$.

LAMB R.J. \& GeRBER G.H. 1985: Effects of temperature on the development, growth, and survival of larvae and pupae of a north-temperate chrysomelid beetle. Oecologia 67: 8-18

LAMB R.J. \& Loschiavo S.R. 1981: Diet, temperature, and the logistic model of developmental rate for Tribolium confusum (Coleoptera: Tenebrionidae). Can. Entomol. 113: 813-818.
Lamb R.J., Gerber G.H. \& Atkinson G.H. 1984: Comparison of developmental rate curves applied to egg hatching data of Entomoscelis americana Brown (Coleoptera: Chrysomelidae). Envir. Entomol. 13: 868-872.

Lamb R.J., Mackay P.A. \& Gerber G.H. 1987: Are development and growth of pea aphids, Acyrthosiphon pisum, in North America adapted to local temperatures? Oecologia 72: $170-177$.

LaUdien H. 1973: Changing reaction systems. In Precht H., Christopherson J., Hensel H., Larcher J. et al.: Temperature and Life. Springer, New York, pp. 355-399.

Leather S.R., WATt A.D. \& Barbour D.A. 1985: The effect of host-plant and delayed mating on the fecundity and lifespan of the pine beauty moth, Panolis flammea (Denis and Schiffermuller) (Lepidoptera: Noctuidae): their influence on population dynamics and relevance to pest management. Bull. Entomol. Res. 75: 641-651.

Liv S.S., ZHANG G.M. \& ZHu J. 1995: Influence of temperature variations on rate of development in insects: analysis of case studies from entomological literature. Ann. Entomol. Soc. Am. 88: 107-119.

Logan J.A., Wollkind D.J., HoYt S.C. \& TANIGOShI L.K. 1976: An analytic model for description of temperature dependent rate phenomena in arthropods. Envir. Entomol. 5: 1135-1140.

Lutz P.E. 1974: Environmental factors controlling duration of larval instars in Tetragoneura cynosura (Odonata). Ecology 55: $630-637$.

LYKOURESSIS D.P. 1985: Temperature requirements of Sitobion avenae (F.) necessary for ecological studies, by assessing methods for the estimation of instar duration. Z. Angew. Entomol. 100: 479-493.

Maeta, Y., Sugiura N. \& Goubara M. 1992: Patterns of offspring production and sex allocation in the small Carpenter bee, Ceratina flavipes Smith (Hymenoptera, Xylocopinae). Jap. J. Entomol. 60: 175-190.

Manel S. \& DebouzIe D. 1997: Logistic regression and continuation ratio models to estimate insect development under variable temperatures. Ecol. Modelling 98: 237-243.

Marshakov V.G. 1984: [Effect of constant and variable temperatures on duration and speed of development of insects.] Entomol. Obozr. 63: 649-657 (in Russian) (Translation in Entomol. Rev. 64[1985]: 1-10).

Matalin A.V. 1998: [Polyvariance of Harpalus (s. str.) affinis Schrank and its adaptive significance.] Izv. Akad. Nauk Ser. Biol. 4: 496-505 (in Russian).

MCDonald J.R., Bale J.S. \& Walters K.F.A. 1997: Effects of sub-lethal cold stress on the western flower thrips, Frankliniella occidentalis. Ann. Appl. Biol. 131: 189-195.

Mrya K. 1965: The embryonic development of a chrysomelid beetle, Atrachya menetriesi Faldermann (Coleoptera, Chrysomelidae). I. The stages of development and changes of external form. J. Fac. Agric. Iwate Univ. 7: 155-166.

Mryashita K. 1997: Breeding and nymphal development of Lycosa coelestis L. Koch. Acta Arachnol. 46: 33-37.

MrYataKe T. 1997: Correlated responses to selection for developmental period in Bactrocera cucurbitae (Diptera: Tephritidae): Time of mating and daily activity rhythms. Behav. Genet. 27: 489-498.

Mryatake T. \& Shimizu T. 1999: Genetic correlations between life-history and behavioral traits can cause reproductive isolation. Evolution 53: 201-208.

Moeur J.E. \& Istock C.A. 1980: Ecology and evolution of the pitcher-plant mosquito. J. Anim. Ecol. 49: 775-792.

Morales-Ramos J.A., Greenserg S.M. \& King E.G. 1996: Selection of optimal physical conditions for mass propagation 
of Catolaccus grandis (Hymenoptera: Pteromalidae) aided by regression. Envir. Entomol. 25: 165-173.

Morita M. \& Tojo S. 1985: Relationship between starvation and supernumerary ecdysis and recognition of the penultimate-larval instar in the common cutworm, Spodoptera litura J. Insect Physiol. 31: 307-313.

Mousseau T.A. \& Dingle H. 1991: Maternal effects in insect life histories. Annu. Rev. Entomol. 36: 511-534.

Musolin D.L. \& SAUlich A.KH. 1995: [Factorial regulation of the seasonal cycle of the stink bug Graphosoma lineatum L. (Heteroptera, Pentatomidae). I. Temperature and photoperiodic responses.] Entomol. Obozr. 74: 736-743 (in Russian) (Translation in Entomol. Rev. 75[1996](9): 84-93).

Mutch R.A. \& Pritchard G. 1986: Development rates of eggs of some Canadian stoneflies (Plecoptera) in relation to temperature. J. N. Am. Benthol. Soc. 5: 272-277.

NeunZIG H.H. 1969: The biology of the tobacco budworm and the corn earworm in North Carolina: with particular reference to tobacco as a host. N. C. Agric. Exp. Stn Tech. Bull. No. $196,76 \mathrm{pp}$.

NishizuKa M., Azuma A. \& Masaki S. 1998: Diapause response to photoperiod and temperature in Lepisma saccharina Linnaeus (Thysanura: Lepismatidae). Entomol. Sci. 1: 7-14.

NyurN S. 1996: Seasonal adaptations in butterflies: A story on plasticity. Entomol. Tidskr. 117: 1-10 (in Swedish).

OCONNOR B.M. 1994: Life-history modifications in astigmatid mites. In Houck M.A. (ed.): Mites: Ecological and Evolutionary Analyses of Life-history Patterns. Chapman and Hall, New York, London, pp. 136-159.

OHNESORGE B. 1979: Beobachtungen zur Biologie der Rubsenblattwespe Athalia rosae L. (Hym., Tenthredinidae). Anz. Schädlingsk. Pflanz. Umweltschutz 52: 70-73.

ØKLAND B. 1991: Laboratory studies of egg development and diapause in Isoperla obscura (Plecoptera) from a mountain stream in Norway. Freshwat. Biol. 25: 485-495.

OKU T. 1983: Aestivation and migration in noctuid moths. In Brown V.K. \& Hodek I. (eds): Diapause and Life Cycle Strategies in Insects. Series Entomologica 23. Junk, The Hague, pp. 219-231.

Pachori R. \& Gargav V.P. 1997: Biology and food preference of Spodoptera litura Fabricius as seedivore. Crop Res. 13: 639-643.

Pritchard G., Harder L.D. \& Mutch R.A. 1996: Development of aquatic insect eggs in relation to temperature and strategies for dealing with different thermal environments. Biol. J. Linn. Soc. 58: 221-244.

Pruess K.P. 1983: Day-degree methods for pest management. Envir. Entomol. 12: 613-619.

Purcell M.F. \& Balcuinas J.K. 1994: Life history and distribution of the Australian weevil Oxyops vitiosa (Coleoptera: Curculionidae), a potential biological control agent for Melaleuca quinquenervia (Myrtaceae). Ann. Entomol. Soc. Am. 87: 867-873.

QueIroz M.M.D.C., Mello R.P.D. \& Freire N.M.D.S. 1996: The effect of different proportions of males and females over the Chrysomya albiceps (Wiedemann 1819) (Diptera, Calliphoridae) biotic potential and longevity under laboratory conditions. Mem. Inst. Oswaldo Cruz 91: 243-247.

Quiring D.T. \& McNeIL J.N. 1985: Effect of larval cannibalism on the development and reproductive performance of Agromyza frontella (Rondani) (Diptera: Agromyzidae). Ann. Entomol. Soc. Am. 78: 429-432.

RAINA A.K., BELl R.A. \& CARLSON R.B. 1977: Influence of temperature on development of an India strain of the pink bollworm in the laboratory and observations on fecundity. Ann. Entomol. Soc. Am. 70: 628-630.
RÉGNIÈRE J. 1982: A process-oriented model of spruce budworm phenology (Lepidoptera: Tortricidae). Can. Entomol. 114: 811-825.

RÉGNIĖRE J. 1984: A method of describing and using variability in development rates for the simulation of insect phenology. Can. Entomol. 116: 1367-1376.

Richard D.S., Saunders D.S., Egan V.M. \& Thomson R.C.K. 1986: The timing of larval wandering and puparium formation in the flesh fly Sarcophaga argyrostoma. Physiol. Entomol. 11: 53-60.

Rrvard D. \& Pilon J.G. 1977: Étude de la variation intra-stade au cours du développement larvaire de Enallagma vernale Gloyd (Zygoptera: Coenagrionidae): discussion sur le mécanisme de différentiation de types de développement. Odonatologica 6: 181-198.

Rrvers D.B. \& Dentinger D.L. 1995: Fecundity and development of the ectoparasitic wasp Nasonia vitripennis are dependent on host quality. Entomol. Exp. Appl. 76: 15-24.

Rodriguez-SAONA C. \& Miller J.C. 1995: Life history traits in Hippodamia convergens (Coleoptera: Coccinellidae) after selection for fast development. Biol. Control 5: 389-396.

RoFr D.A. 1992: The Evolution of Life Histories, Theory and Analysis. Chapman and Hall, New York, $535 \mathrm{pp}$.

Rürm W. 1970: Zur Phänologie von Boophthora erythrocephala De Geer (Simuliidae, Diptera). Z. Angew. Zool. 57: 385-408.

RYAN R.B. 1962: Durations of the immature stadia of Coeloides brunneri at various constant temperatures, with descriptions of the five larval instars. Ann. Entomol. Soc. Am. 55: 403-409.

SABELIS M.W. \& JANSSEN A. 1994: Evolution of life-history patterns in the Phytoseiidae. In Houck M.A. (ed.): Mites: Ecological and Evolutionary Analyses of Life-History Patterns. Chapman and Hall, New York, London, pp. 70-98.

SAKuraI T. 1998: Variation in time to sperm depletion and oviposition patterns in females of Riptortus clavatus (Heteroptera: Alydidae). Ann. Entomol. Soc. Am. 91: 737-740.

SCHAFFER P.L. 1983: Prediction of variation in development period of insects and mites reared at constant temperatures. Envir. Entomol. 12: 1012-1019.

SChNeIDERMann H.A. \& Williams C.M. 1953: The physiology of insect diapause. VII. The respiratory metabolism of the Cecropia silkworm during diapause and development. Biol. Bull. Mar. Biol. Lab., Woods Hole 105: 320-334.

Sharpe P.J.H. \& DeMrchele D.W. 1977: Reaction kinetics of poikilotherm development. J. Theor. Biol. 64: 649-670.

Silva C.L.G.D., Santos A.C.G., Cunha D.W., Daemon E. \& FACCINI J.L.H. 1997: Effect of different relative humidities on the biology of non parasitic phase of Anocentor nitens (Neumann) Schulze, 1937 (Acari: Ixodidae). Rev. Brasil. Parasitol. Vet. 6: 29-32.

SмIтн L. 1993: Effect of humidity on life history characteristics of Anisopteromalus calandrae (Hymenoptera: Pteromalidae) parasitizing maize weevil (Coleoptera: Curculionidae) larvae in shelled corn. Envir. Entomol. 22: 618-624.

Socha R. \& Śula J. 1996: Differences in haemolymph proteins in relation to diapause and wing dimorphism in Pyrrhocoris apterus (L.) (Heteroptera: Pyrrhocoridae). J. Comp. Physiol. (B) (Biochem. Syst. Envir. Physiol.) 166: 382-387.

SotA T. 1994: Variation of carabid life cycles along climatic gradients: An adaptive perspective for life-history evolution under adverse conditions. In Danks H.V. (ed.): Insect LifeCycle Polymorphism: Theory, Evolution and Ecological Consequences for Seasonality and Diapause Control. Series Entomologica 52. Kluwer Academic Publishers, Dordrecht, pp. 91-112. 
Sota T. \& Mogr M. 1995: Geographic variation in the expression of autogeny in Aedes togoi (Diptera: Culicidae) under different temperature and photoperiod conditions. J. Med. Entomol. 32: 181-189.

SPENCE J.R. 1989: The habitat templet and life history strategies of pond skaters (Heteroptera: Gerridae): reproductive potential, phenology, and wing dimorphism. Can. J. Zool. 67: $2432-2447$.

Spurgeon D.W., Raulston J.R., Lingren P.D. \& Shaver T.N. 1997: Mexican rice borer (Lepidoptera: Pyralidae) reproductive responses to delayed mating. SWest. Entomol. 22 195-200.

Stam E.M., Van De Leemkule M.A. \& Ernsting G. 1996: Trade-offs in the life history and energy budget of the parthenogenetic collembolan Folsomia candida (Willem). Oecologia 107: 283-292.

STEARNS S.C. 1992: The Evolution of Life Histories. Oxford University Press, New York, 249 pp.

StrickMan D., Sithiprasasna R. \& Southard $\quad$ D. 1997 Bionomics of the spider, Crossopriza lyoni (Araneae, Pholcidae), a predator of dengue vectors in Thailand. J. Arachnol. 25: 194-201.

SunOSE T. 1985: Population regulation of the euonymus gall midge Masakimyia pustulae Yukawa and Sunose (Diptera: Cecidomyiidae) by hymenopterous parasitoids. Res. Popul. Ecol. 27: 287-300.

Tauber C.A., Johnson J.B. \& Tauber M.J. 1992: Larval and developmental characteristics of the endemic Hawaiian lacewing, Anomalochrysa frater (Neuroptera: Chrysopidae). Ann. Entomol. Soc. Am. 85: 200-206.

TAYLOR F. 1981: Ecology and evolution of physiological time in insects. Am. Nat. 117: 1-23.

Tepedino V.J. \& Torchio P.F. 1982: Temporal variability in the sex ratio of a non-social bee, Osmia lignaria propinqua: Extrinsic determination or the tracking of an optimum? Oikos 38: $177-182$.

Topp W. 1994: Seasonal time partitioning and polymorphism in the developmental cycles of sympatric Staphylinoidea (Coleoptera) living in an unstable environment. In Danks H.V. (ed.): Insect Life-Cycle Polymorphism: Theory, Evolution and Ecological Consequences for Seasonality and Diapause Control. Series Entomologica 52. Kluwer Academic Publishers, Dordrecht, pp. 277-312.

Trost L.M.W. \& Berner L. 1963: The biology of Callibaetis floridanus Banks (Ephemeroptera: Baetidae). Fla Entomol. 46: $285-299$.

TURNOCK W.J. \& BoIvIN G. 1997: Inter- and intra-population differences in the effects of temperature on postdiapause development of Delia radicum. Entomol. Exp. Appl. 84: 255-265.

UnNITHAN G.C. \& Delobel A.G.L. 1985: Effects of temperature on longevity, fecundity and fertility of the sorghum shootfly, Atherigona soccata Rondani. Insect Sci. Appl. 6: 513-516.

Valicente F.H. \& O'NeIL R.J. 1995: Effect of host plants and feeding regimes on selected life history characteristics of Podisus maculiventris (Say) (Heteroptera: Pentatomidae). Biol. Control 5: 449-461.

Vaught G.L. \& Stewart K.W. 1974: The life history and ecology of the stonefly Neoperla clymene (Newman) (Plecoptera: Perlidae). Ann. Entomol. Soc. Am. 67: 167-178.

VICKERS R.A. 1997: Effect of delayed mating on oviposition pattern, fecundity and fertility in codling moth, Cydia pomonella (L.) (Lepidoptera: Tortricidae). Austr. J. Entomol. 36: 179-182.

Wagner T.L., Wu H.I., Sharpe P.J.H. \& Coulson R.N. 1984a: Modeling distributions of insect development time: a literature review and application of the Weibull function. Ann. Entomol. Soc. Am. 77: 475-487.
Wagner T.L., Wu H.I., Sharpe P.J.H., Schoolfield R.M. \& Coulson R.N. 1984b: Modeling insect development rates: a literature review and application of a biophysical model. Ann. Entomol. Soc. Am. 77: 208-225.

Wagner T.L., Wu H.I., Feldman R.M., Sharpe P.J.H. \& Coulson R.N. 1985: Multiple-cohort approach for simulating development of insect populations under variable temperatures. Ann. Entomol. Soc. Am. 78: 691-704.

Wagner T.L., Hennier P.B., Flamm R.O. \& Coulson R.N. 1988: Development and mortality of Ips avulsus (Coleoptera: Scolytidae) at constant temperatures. Envir. Entomol. 17: 181-191.

Waldbauer G.P., Marciano A.P. \& Pathak P.K. 1980: Lifespan and fecundity of adult rice leaf folders, Cnaphalocrocis medinalis (Guenée) (Lepidoptera: Pyralidae), on sugar sources, including honeydew from the brown planthopper, Nilaparvata lugens (Stål) (Hemiptera: Delphacidae). Bull. Entomol. Res. 70: 65-71.

Wanjama J.K. \& Holliday N.J. 1987: Paedogenesis in the wheat aphid Schizaphis graminum. Entomol. Exp. Appl. 45: 297-298.

WASSERMAN S.S. \& AsAmI T. 1985: The effect of maternal age upon fitness of progeny in the southern cowpea weevil Callosobruchus maculatus. Oikos 45: 191-196.

Westfall M.J. JR. 1987: Order Odonata. In Stehr F.W. (ed.): Immature Insects. Kendall/Hunt, Dubuque, pp. 95-117.

Whittaker R.H. \& GoOdman D. 1979: Classifying species according to their demographic strategy. I. Population fluctuations and environmental heterogeneity. Am. Nat. 113: $185-200$.

WigGins G.B. 1973: A contribution to the biology of caddisflies (Trichoptera) in temporary pools. Contrib. Life Sci. Div., R. Ont. Mus. 88: 1-28.

Wiggins G.B., Mackay R.J. \& SMith I.M. 1980: Evolutionary and ecological strategies of animals in annual temporary pools. Arch. Hydrobiol. Suppl. 58: 97-206.

Wigglesworth V.B. 1972: The Principles of Insect Physiology. 7 th ed. Chapman and Hall, London, $827 \mathrm{pp}$.

WiLKINSON C. 1981: Modern biosystematics. Entomol. Gaz. 32: 205-215.

WiLson G.G. 1980: Effects of Nosema fumiferanae (Microsporida) on rearing stock of spruce budworm, Choristoneura fumiferana (Lepidoptera: Tortricidae). Proc. Entomol. Soc. Ont. 111: 115-116.

WISSINGER S.A. 1997: Cyclic colonization in predictably ephemeral habitats: a template for biological control in annual crop systems. Biol. Control 10: 4-15.

WoOD D.M., DAng P.T. \& Eluis R.A. 1979: The mosquitoes of Canada (Diptera: Culicidae). The insects and arachnids of Canada. Part 6. Agric. Can. Publ. No. 1686, 390 pp.

Wrensch D.L. \& BruCE W.A. 1991: Sex ratio, fitness and capacity for population increase in Pyemotes tritici (L.-F. \& M.) (Pyemotidae). In Schuster R. \& Murphy P.W. (eds.): The Acari. Reproduction, Development and Life-history Strategies. Chapman and Hall, London, pp. 209-221.

Yu D.S.K., Hagley E.A.C. \& Laing J.E. 1984: Biology of Trichogramma minutum Riley collected from apples in southern Ontario. Envir. Entomol. 13: 1324-1329.

Zera A.J. \& Denno R.F. 1997: Physiology and ecology of dispersal polymorphism in insects. Annu. Rev. Entomol. 42: 207-231.

ZHANG Z-Q. 1995: Variance and covariance of ovipositional rates and developmental rates in the Phytoseiidae (Acari: Mesostigmata): A phylogenetic consideration. Exp. Appl. Acarol. 19: 139-146.

Received January 18, 2000; accepted May 29, 2000 